Document downloaded from:

http://hdl.handle.net/10251/103634

This paper must be cited as:

Prudhom, A.; Antonino-Daviu, J.; Razik, H.; Climente Alarcon, V. (2017). Time-frequency vibration analysis for the detection of motor damages caused by bearing currents. Mechanical Systems and Signal Processing. 84:747-762. doi:10.1016/j.ymssp.2015.12.008

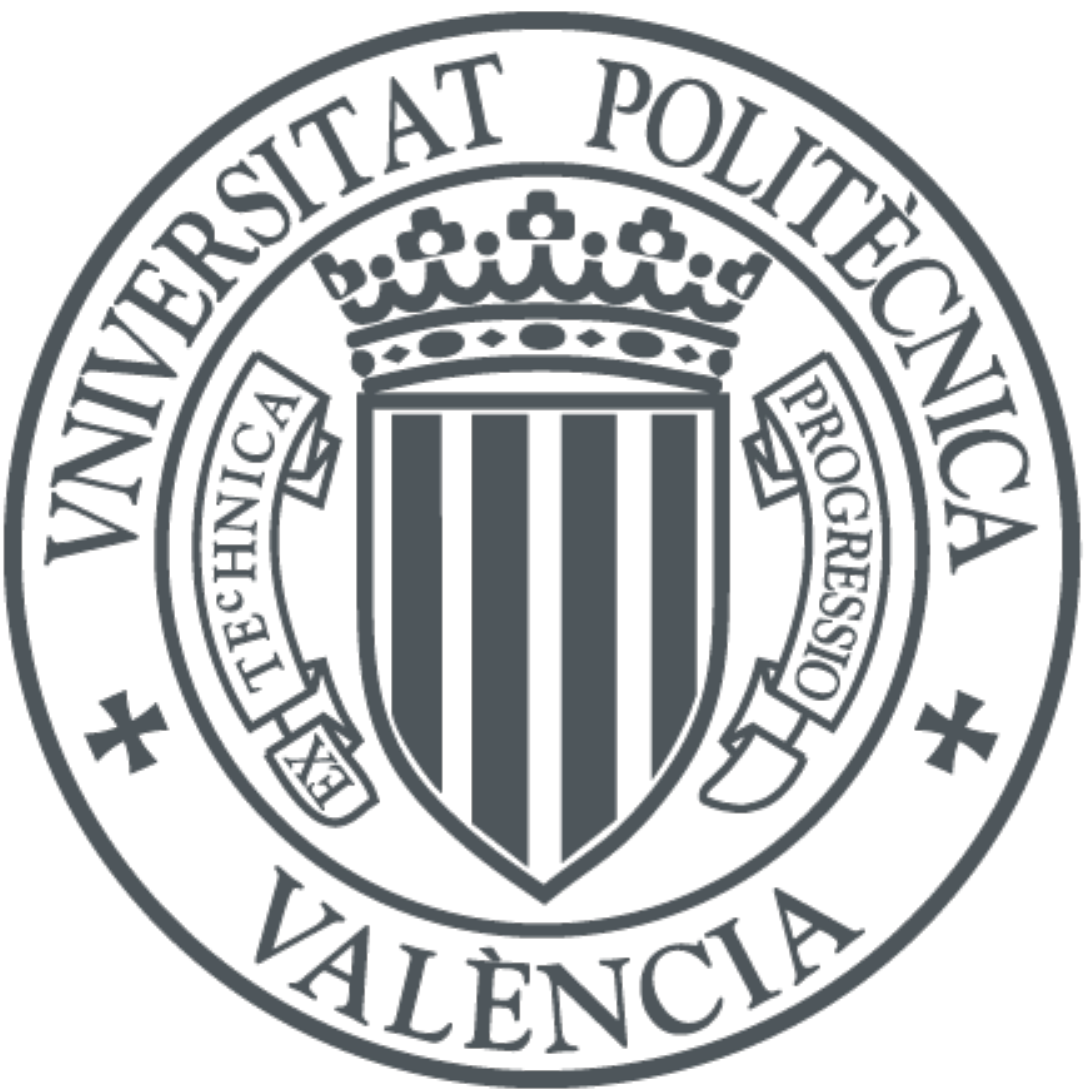

The final publication is available at

http://doi.org/10.1016/j.ymssp.2015.12.008

Copyright Elsevier

Additional Information 


\title{
Time-frequency vibration analysis for the detection of motor damages caused by bearing currents
}

\begin{tabular}{|c|c|c|}
\hline Aurelien Prudhom ** & Hubert Razik* & Vicente Climente-Alarcon $* * *$ \\
\hline \multicolumn{3}{|c|}{$* *$} \\
\hline * Universidad Politécnica de Valencia & **Université Claude Bernard Lyon 1 & *** Aalto University \\
\hline Instituto Tecnológico de la Energía (ITE) & Laboratoire AMPERE - UMR 5005 & Department of Electrical Engineering and \\
\hline Camino de Vera s/n & Bâtiment Oméga - & Automation \\
\hline 46022 Valencia, SPAIN & 43 bd du 11 novembre 1918 & P. O. Box 13000 \\
\hline Phone: +34-96-3877592, & 69622 Villeurbanne, FRANCE & FI-00076 Aalto, FINLAND \\
\hline Fax: +34-96-3877599 & Phone: $+33(0)-472431230$ & e-mail: viclial@ieee.org \\
\hline e-mail: joanda@die.upv.es & Fax: $+33(0)-472431193$ & \\
\hline & e-mail: hubert.razik@univ-lyon1.fr & \\
\hline
\end{tabular}

\begin{abstract}
Motor failure due to bearing currents is an issue that has drawn an increasing industrial interest over recent years. Bearing currents usually appear in motors operated by variable frequency drives (VFD); these drives may lead to common voltage modes which cause currents induced in the motor shaft that are discharged through the bearings. The presence of these currents may lead to the motor bearing failure only few months after system startup. Vibration monitoring is one of the most common ways for detecting bearing damages caused by circulating currents; the evaluation of the amplitudes of well-known characteristic components in the vibration Fourier spectrum that are associated with race, ball or cage defects enables to evaluate the bearing condition and, hence, to identify an eventual damage due to bearing currents. However, the inherent constraints of the Fourier transform may complicate the detection of the progressive bearing degradation; for instance, in some
\end{abstract}


cases, other frequency components may mask or be confused with bearing defect-related while, in other cases, the analysis may not be suitable due to the eventual non-stationary nature of the captured vibration signals. Moreover, the fact that this analysis implies to lose the time-dimension limits the amount of information obtained from this technique. This work proposes the use of time-frequency (TF) transforms to analyse vibration data in motors affected by bearing currents. The experimental results obtained in real machines show that the vibration analysis via T-F tools may provide significant advantages for the detection of bearing current damages; among other, these techniques enable to visualize the progressive degradation of the bearing while providing an effective discrimination versus other components that are not related with the fault. Moreover, their application is valid regardless of the operation regime of the machine. Both factors confirm the robustness and reliability of these tools that may be an interesting alternative for detecting this type of failure in induction motors.

\section{INTRODUCTION}

Over recent years, many industrial users have reported bearing damages in motors operated with variable frequency drives (VFD). After intensive research in the area, most of these failures have been attributed to the appearance of bearing currents caused by the VFD operation [1]. More specifically, these currents are due to the existence of a common mode voltage in the drive system; as pointed out in [2], while a typical three-phase sinusoidal power supply is balanced and symmetrical under normal operation conditions (hence, the neutral is at zero level), in a PWM switched three phase power supply, perfect balance between phases is not achieved instantaneously; this causes a potential between the inverter output and earth which will force currents through stray impedances in the motor cables and motor windings (this is known as common mode current [2]).

More concretely, different studies have revealed that bearing currents can be classified into several categories, each of them having different origin [3]. Depending on aspects as motor size, one or other 
type of current will prevail. In small motors (rated less than $30 \mathrm{~kW}$ ), the common mode voltage will cause a voltage drop between the inner and outer race of the bearing. This will create high frequency bearing current pulses that will flow through the capacitive coupling of both races. This can happen in installations where the shaft is not grounded via the driven machinery [2, 4-5]. On the other hand, in large motors (with rated powers above $100 \mathrm{~kW}$ and frame sizes above IEC 315 [2]) high frequency bearing currents are induced in the motor shaft due to asymmetrical flux distribution in the motor. Voltage pulses fed by the inverter contain such high frequencies, that the capacitances between the motor windings and its frame provide paths for currents to leak to earth. This will induce a voltage difference between the ends of the shaft. If this voltage difference is high enough to reach the breakdown voltage of the bearing oil film, a current will flow through the bearing [2, 5]. A third type of bearing current may circulate when the VFD common voltage mode saturates the stator winding capacitance and it discharges via the grounding system. The leakage current returns to the inverter via the grounding circuit, seeking the lowest impedance paths. If the motor shaft is grounded via the load and impedance path to the load is low, a part of the leakage current can flow through the bearings, shaft and driven machinery back to the inverter. This third type of bearing current is known as shaft grounding current; it is caused by poor stator grounding and only appears if the coupling motor-load is conductive [2]. It can appear for any motor size.

The circulation of these currents may lead to shorten the life of the bearings: although failure rates may vary widely depending on many factors, evidence suggests that a significant portion of failures occur only 3 to 12 months after the system starts its operation $[4,6]$. Bearing currents may damage the contact surface on the bearing balls as well as the bearing rings. The metal is progressively heated and small craters may appear on the surface of the material (arcing, pitting and fluting of the bearing race). This effect is often accompanied by a discoloration in the balls. Fig. 1 shows the picture of a real bearing that was damaged due to the circulation of bearing currents: note the damaged inner ring with a 
characteristic washboard pattern caused by fluting effect [1, 4] (Fig. 1(a)). Note also the characteristic matt grey colour of the balls (Fig.2).

To mitigate the effects of shaft currents, two main strategies have been proposed $[4,6]$. These are based on diverting the induced shaft current from the bearings by: 1) insulating the bearings and/or 2) providing an alternative path to ground. Based on these strategies there are a number of technologies nowadays available in the market: Faraday shields, insulated bearings, ceramic bearings, conductive grease, grounding brush, bearing protection rings, etc...However, as [6] points out, few of them meet all the criteria of effectiveness, low cost, and application versatility. Due to these facts, the real implantation of these technologies to prevent bearing currents is still scarce in many industrial sites.

Vibration monitoring is widely employed to detect bearing damages (provoked by either bearing currents or other causes) [7-10]. The evaluation of characteristic frequency components in the vibration spectrum may help to determine the condition of the different parts of the bearing and, eventually, to detect the progressive degradation in any of these parts. In spite of its widespread use, this technique has also drawbacks. Most of them rely on the inherent constraints of the underlying signal processing tool, the Fast Fourier Transform (FFT); the application of this technique implies that time information is lost, i.e., FFT is capable to extract the frequency components present in the signal but not how they evolve over time (a fact that limits the amount of information obtained with this tool, since it becomes difficult to analyse how the amplitude of a certain fault component increases over time, unless repeated FFT analyses are carried out). In addition, fault related components may fall near other components that are not related to the failure, a fact that complicates the reliable diagnosis of the failure or may even lead to a wrong diagnostic [11-14]. Finally, the tool is not suitable in variable speed applications, since the slip-dependant fault frequencies may move (as the speed varies) spreading through the spectrum, becoming hence impossible to evaluate their real amplitude (unless complex algorithms are applied) [15]. 
The present paper proposes the use of time-frequency tools to overcome some of the drawbacks, as well as to complement, the conventional FFT analysis. These tools have been recently applied with great success in the induction motor condition monitoring field, but mainly for the diagnostic of other failures as rotor damages or eccentricities [11, 13, 15-17], although some works related to their application to bearing fault detection have also shown promising results [18-22]. The main advantage of T-F tools is that they can analyse any machine quantity regardless of the machine operation regime, preserving the time information. In other words, these tools provide a full picture of the time-frequency content of the analyse signal, so they are capable to identify not only which frequencies are present but also how they evolve over time. The identification of the time-frequency evolutions of fault components may be very useful to discriminate them versus other possible components present in the analysed quantity. Moreover, these tools may enable to visualize, in a single plot, how the fault-related frequency components increase the amplitude as the fault worsens. This paper shows the powerfulness of these tools to track the harmonics associated with bearing damages provoked by the circulation of bearing currents. The results are obtained from experiments with real motors and they prove the potential of these tools for becoming a useful informational source for the reliable diagnostic of the fault.

\section{DETECTION OF BEARING CURRENTS VIA VIBRATION ANALYSIS}

In industry, bearing damages are usually detected by a loud running noise, or by using continuous vibration monitoring [2]. When a damaged bearing is detected, it should be replaced before its total destruction causes production downtimes. As commented above, the damage can be verified if the rolling tracks of the bearing are fluted or frosted, and the rolling elements have a grey, dull finish [2].

The analysis of the vibration spectrum has been a common manner to detect damages in different parts of the bearing. The amplification of particular frequencies in the Fourier spectrum of vibration 
data that depend on the constructive characteristics of the bearing, enables to identify the degradation of a ball bearing. More specifically, expressions (1) to (4) are commonly employed to calculate the frequencies associated to damages in the outer race (1), inner race (2), bearing balls (3) and cage (4) [23-24]. Note that these expressions depend on constructive parameters of the bearings (see Fig. 2), as well as other characteristics: $f_{C}$ is the cage fault frequency, $f_{I}$ is the inner raceway fault frequency, $f_{O}$ is the outer raceway fault frequency, $f_{B}$ is the ball/roller fault frequency, $N_{b}$ is the number of rolling elements, $D_{b}$ and $D_{c}$ are the diameter of the balls and the pitch diameter, respectively, $f_{r}$ is the mechanical rotor frequency and $\beta$ is the ball contact angle (see Fig. 2).

$$
\begin{aligned}
& f_{O}=\frac{N_{b}}{2} \cdot f_{r} \cdot\left(1-\frac{D_{b}}{D_{p}} \cdot \cos \beta\right) \\
& f_{I}=\frac{N_{b}}{2} \cdot f_{r} \cdot\left(1+\frac{D_{b}}{D_{p}} \cdot \cos \beta\right) \\
& f_{B}=\frac{D_{p}}{D_{b}} \cdot f_{r} \cdot\left(1-\frac{D_{b}^{2}}{D_{p}^{2}} \cdot \cos ^{2} \beta\right) \\
& f_{C}=\frac{1}{2} \cdot f_{r} \cdot\left(1-\frac{D_{b}}{D_{p}} \cdot \cos \beta\right)
\end{aligned}
$$

In the present work, two different bearings will be considered (see pictures in Fig. 3). The bearing models are SKF Explorer 6204 and SKF Explorer 6202. These are deep grove, single row ball bearings. The main reason for selecting these models was that they enable a quick and reliable disassembly so that it was possible an easy access to each component. The bearing parameters taken from the data sheet are shown in Table I. 
Table I. Parameters of the considered bearings

\begin{tabular}{|l|c|c|}
\hline & \multicolumn{2}{|c|}{ MODEL } \\
\hline PARAMETER & $\begin{array}{c}\text { SKF Explorer } \\
\mathbf{6 2 0 4}\end{array}$ & $\begin{array}{c}\text { SKF Explorer } \\
\mathbf{6 2 0 2}\end{array}$ \\
\hline Outer diameter $\left(\boldsymbol{D}_{\boldsymbol{o}}\right)$ & $39.7 \mathrm{~mm}$ & $29.2 \mathrm{~mm}$ \\
\hline Inner diameter $\left(\boldsymbol{D}_{\boldsymbol{}}\right)$ & $29.3 \mathrm{~mm}$ & $21.7 \mathrm{~mm}$ \\
\hline Ball diameter $\left(\boldsymbol{D}_{\boldsymbol{b}}\right)$ & $7.92 \mathrm{~mm}$ & $6.35 \mathrm{~mm}$ \\
\hline Pitch diameter $\left(\boldsymbol{D}_{\boldsymbol{p}}\right)$ & $34.5 \mathrm{~mm}$ & $25.4 \mathrm{~mm}$ \\
\hline Contact angle $(\boldsymbol{\beta})$ & 0 & 0 \\
\hline Number of balls $\left(\boldsymbol{N}_{\boldsymbol{b}}\right)$ & 8 & 8 \\
\hline
\end{tabular}

Considering that in the tests the motor under study was supplied through a frequency converter that set the supply frequency so that the mechanical rotor frequency was $50.3 \mathrm{~Hz}$ (see Section 4 for the description of the experiments), the frequencies associated with the different bearing defects, given by expressions (1) to (4) are those shown in Table II. The evaluation of the amplitude of these components in the vibration spectrum is the basis of the usual approach to detect bearing failures.

Table II. Fault frequencies for each bearing considering that $f_{r}=50.3 \mathrm{~Hz}$

\begin{tabular}{|c|c|c|}
\hline & \multicolumn{2}{|c|}{ MODEL } \\
\hline FAULT FREQUENCY & $\begin{array}{c}\text { SKF Explorer } \\
\mathbf{6 2 0 4}\end{array}$ & $\begin{array}{c}\text { SKF Explorer } \\
\mathbf{6 2 0 2}\end{array}$ \\
\hline Outer raceway damage $\left(\boldsymbol{f}_{O}\right)$ & $154.98 \mathrm{~Hz}$ & $151 \mathrm{~Hz}$ \\
\hline Inner raceway damage $\left(\boldsymbol{f}_{I}\right)$ & $247.42 \mathrm{~Hz}$ & $251.40 \mathrm{~Hz}$ \\
\hline Ball fault frequency $\left(\boldsymbol{f}_{B}\right)$ & $103.71 \mathrm{~Hz}$ & $94.52 \mathrm{~Hz}$ \\
\hline Cage fault frequency $\left(\boldsymbol{f}_{C}\right)$ & $19.37 \mathrm{~Hz}$ & $18.87 \mathrm{~Hz}$ \\
\hline
\end{tabular}

\section{TIME-FREQUENCY TOOLS}

Over recent years, time-frequency tools have been applied with profusion in the induction motors condition monitoring area $[11,13,15-21]$. The addition of a further dimension to the analysis provides important advantages in comparison with the traditional techniques relying on stationary methods [11]. For instance, they can be employed for the analysis of varying-frequency machine quantities; as an example, the decomposition of the motor starting current using time-frequency transforms have proven to be a robust informational source for assessing the rotor condition as well as for diagnosing other 
failures as eccentricities by studying its related components during the acceleration stage $[11,13,15$ 17]. These tools have been also applied to the analysis of non-stationary signals of other quantities, as vibrations caused by bearings at its early stage of degradation [25] or even noises [26].

Time-frequency tools provide a representation of the analysed signal into a time-frequency map. Hence, they enable to visualize how the frequencies of eventual fault-related components evolve over time. The evolutions of these components lead to very characteristic t-f patterns that can be employed to diagnose the presence of the failure $[11,28]$. The use of these characteristic patterns provides a high reliability for the diagnostic of the motor condition and avoids eventual false indications of the traditional methods $[11,13,28]$. Moreover, the computation of the energy or other features such as the entropy [25] at certain predefined regions of the time-frequency map enables to define fault indicators to determine the severity of the failure.

There are many time-frequency tools that have been satisfactorily applied for the diagnosis of different motor faults. In qualitative terms, time-frequency transforms can be divided into two main types: discrete and continuous [27]. Each of these groups has its own characteristics and advantages for the diagnosis. Fig. 4 depicts a schematic representation of the main features of each group that were well discussed in previous papers [27-28].

The present work focuses on the application of continuous tools for the detection of damages caused by bearing currents. Continuous time-frequency tools can be divided into two main classes [27-28]:

1) Tools based on correlation with t-f atoms: these tools correlate the analysed signal with a set of functions called time-frequency atoms. These are functions whose energy is well concentrated around a point in the t-f plane. The Short Time Fourier Transform (STFT) or the Continuous Wavelet Transform (CWT), among other, belong to this group. The main drawback of these transforms stems from the fact that segmenting the signal in order to locate the instants of 
appearance of its components reduces the discrimination in frequency, since being time and frequency complementary variables, the resolution of a t-f diagram cannot be improved in both dimensions at the same time in agreement with the Uncertainty Principle. Hence, it becomes necessary a trade-off between time and frequency resolutions (this trade-off is constant in the STFT while variable in the CWT) [28].

2) Quadratic distributions: these tools are based on correlating the analysed signal with a time and frequency translation of itself. The main representative is the Wigner-Ville Distribution (WVD). The WVD is aimed to obtain an accurate t-f energy density localization with no need of windowing. Its resolution it only depends on the length of the analysed signal (no trade-off). The main drawback of the WVD is the appearance of an extra oscillatory term in the t-f plane for each pair of the signal real components (cross terms). To avoid this constraint, there are several solutions such as smoothing the result or filtering the correlation with a function called kernel which leads to the loss of either resolution or other desirable properties. Depending on the kernel used, a new quadratic distribution is defined [28].

In the present paper, due to the nature of the fault components to be tracked in the time-frequency plane and its widespread use, the STFT is employed, although other options as CWT, WVD, etc... are also perfectly suitable. The foundations of this tool are well-known; the signal to be analysed is multiplied by a window function centered at $t$ that is different from zero only for a short time period [29], thus studying the signal just in that interval. The mathematical expression of this process is given by (5), where $h(\tau)$ is the window function (usually, a Hann window or a Gaussian window although other functions are also possible, and $x(\tau)$ is the analysed signal.

$$
x_{t}(\tau)=\frac{1}{\sqrt{2 \cdot \pi}} \cdot \int_{-\infty}^{\infty} x(\tau) \cdot h(\tau-t) d \tau
$$


The Fourier transform of the resulting signal is obtained, while the window function is moved along the time axis, resulting a two-dimensional representation of the signal:

$$
X_{t}(\omega)=\frac{1}{\sqrt{2 \cdot \pi}} \cdot \int_{-\infty}^{\infty} x(\tau) \cdot h(\tau-t) e^{-j \omega t} \cdot d \tau
$$

A set of spectra are obtained in such way; the total set is known as $P_{S P}(t, w)$, which is a timefrequency representation of the analyzed signal (also known as spectrogram).

\section{EXPERIMENTS.}

Laboratory experiments were developed using the test bench depicted in Fig. 5. An induction motor was driven through a frequency converter that set the supply frequency at $50.3 \mathrm{~Hz}$. The rated characteristics of the motor were: rated power $P_{n}=0.45 \mathrm{~kW}$, rated speed $n_{n}=2830$ r.p.m, rated voltage $U_{n}=380 / 220 \mathrm{~V}$, rated frequency $=50 \mathrm{~Hz}$ and power factor $\cos \varphi=0.79$. One of the motor bearings was the SKF 6202 model; this bearing was showing incipient signs of damage due to its prolonged use. In the opposite border to the motor shaft, the tested SKF 6204 bearing was mounted.

A high frequency voltage was applied between the bearing cage and the shaft $(211 \mathrm{kHz})$, using a pulse generator based on a MOSFET circuit. The RMS value of the applied voltage applied was $5 \mathrm{~V}$, while the average value of the resulting current pulses was variable but did not surpass a level of 1 A. Fig. 6 shows the waveforms of the applied voltage (top line, orange colour) and current pulses (bottom line, blue colour).

As a consequence, the experimental assembly was simulating the circulation of a bearing current that was flowing through the bearing and through the shaft (see Fig. 5). The bearing currents were injected during consecutive time intervals with variable duration (these intervals will be denoted by T1 to T26). During the tests, vibration data were captured at different points of the test bed at a sampling rate of 20 
kHz. Fig. 7 shows a detail of the location of the accelerometers to capture vibration signals; the four measurement points are numbered in the figure to facilitate the identification of the vibration signals that are analysed in the following sections.

\section{ANALYSES AND DISCUSSION.}

In this section, the considered time-frequency decomposition tool (STFT) will be applied to the vibration signals that were captured at the different measurement points (2 to 5). Due to the huge amount of data (the vibration signals were registered during 26 time intervals, each of them having a minimum duration of 100 seconds) only few of these intervals will be represented for simplicity purposes (intervals T4, T14 and T25). Each time-frequency analysis shows the time evolution of the considered frequency components during the represented time intervals. Also, the figures do not represent the full time-frequency map but they will show the time-frequency region of interest in each case, where the fault components associated with the bearing faults are located.

\subsection{Measurement point 2 (y-radial direction on the SKF 6204 bearing).}

Figs. 8 and 9 show the time-frequency decompositions of the vibration signals at point 2 in the three considered time intervals (T4, T14 and T25). The figures only plot the frequency regions under interest (145-160 Hz) for Fig. 8 and (245-270 Hz) for Fig.9.

With regards to Fig. 8, note how the frequency component at around $154 \mathrm{~Hz}$ associated with the outer raceway damage in the bearing SKF 6204, in which the currents where injected (see $f_{O}$ in Table II) progressively increases its amplitude as the severity of the failure gets worse due to the circulation of these bearing currents (note the more intense colour in interval T25 in comparison with the intervals T14 and T4, where the development of the fault was more incipient). Note also that there is slight 'displacement' of that frequency between T14 and T25 (the frequency is slightly higher in T25). On 
the other hand, note that there is a very slight component at around $151 \mathrm{~Hz}$ (which is almost unadvertised in that figure). This component is due to the degradation of the outer raceway of SKF 6202 due to its prolonged use (see frequency $f_{O}$ in Table II); the amplitude of this component is more stable over time and has a much smaller value than the component associated to the failure in SKF 6204.

In Fig. 9, note that the amplitude of the component at around 247-248 Hz associated to the bearing failure in the inner raceway of SKF 6204 (see $f_{I}$ in Table II) remains almost constant from T4 to T14. However, the component at near $251 \mathrm{~Hz}$ (associated with the inner raceway failure in SKF 6202) increases from T4 to T14, hence revealing a progressive degradation of this bearing (see Table II).

\subsection{Measurement point 4 (z-radial direction on the SKF 6204 bearing).}

Fig. 10 is equivalent to Fig. 8 but for point 4 instead of point 2 (see Fig. 7). Again, the figure only plots the frequency region under interest (145-160 Hz). Fig. 10 shows a quite similar behaviour of the fault components in the [145-160] Hz region as that shown in Fig. 8. The fault component associated to the damage in the outer raceway of SKF 6204 (around $154 \mathrm{~Hz}$, see Table II) shows a prominent increment (especially from T14 to T25) that reflects the progressive damage in the outer raceway due to the injection of bearing currents. On the other hand, the amplitude of the component at around 151 $\mathrm{Hz}$ remains approximately constant (despite a slight increase in the interval T14); again, this may be linked with the inherent damage of SKF 6202 due to prolonged use.

This figure reveals, once again, the ability of the time-frequency, tools to discriminate the components linked with the different bearings and at the same time, analyse their evolution in amplitude over time. 
Fig. 11 depicts the time-frequency analysis for the time intervals T4 and T14, circumscribed to the frequency band [245-255] Hz. Note, again, the prominent amplitude increment for the component associated to the SKF 6202 inner raceway damage.

\subsection{Measurement point 5 (axial direction on the SKF 6204 bearing).}

Fig. 12 depicts the time-frequency analysis of the vibration signals captured at point 5 during the three intervals (T4, T14 and T25); the graph is restricted to the frequency interval [145-160] Hz. Note that it is clearly evident the progressive increment in amplitude of the component associated with the damage in the outer raceway $\left(f_{O}\right)$ for bearing SKF 6204 (component around $154 \mathrm{~Hz}$ ), which is provoked by the current injection in this bearing. On the other hand, the component at around $151 \mathrm{~Hz}$ (which is linked to the damage in the outer raceway of SKF 6202) has relatively low amplitude that remains almost constant, as observed in the graph.

Fig. 13 shows the time-frequency analysis for the time intervals T4 and T14, circumscribed to the frequency band [245-254] Hz. Note, the amplitude increment for the component associated to the SKF 6202 inner raceway damage (around $251 \mathrm{~Hz}$, see Table II). Also note that the significant amplitude of the component associated with the SKF 6204 inner raceway failure. Once again, time-frequency tools provide the possibility of discriminating between the components caused by the failures at the different bearings.

\subsection{Measurement point 3 (y-radial direction on the motor frame).}

Fig. 14 depicts the time-frequency analysis of the vibration signals captured at point 3 during the intervals (T4, T14 and T25); only the frequency range [145-160] Hz is plotted. Note that in this case, since the vibration measurement point is over the motor frame, much nearer to bearing SKF 6202 than to SKF 6204 (see Fig. 7), the effects of the failure in the nearest bearing are much more noticeable. Hence, the component at around $151 \mathrm{~Hz}$, which is associated to the outer raceway damage in bearing 
SKF 6202 (see Table II) is much more prominent than that at around $154 \mathrm{~Hz}$ (caused by the damage in SKF 6204). In any case, the time-frequency analysis, once again, enables to discern between the components caused by different bearings and to detect their progressive increase in amplitude over time.

Fig. 15 shows the time-frequency analysis for the time intervals T4 and T14 for the frequency range [245-254] Hz. Note, again, the amplitude increment for the component associated to the SKF 6202 inner raceway damage (around $251 \mathrm{~Hz}$, see Table II). Also note the presence of the component associated with the SKF 6204 inner raceway failure. Note that while the amplitude of the component associated with the SKF 6202 failure is larger, that of the component linked to SKF 6204 is lower than for the previous measurement points, due to the fact that measurement point 3 is much nearer to the first bearing than to the second. In any case, once again, time-frequency tools allow discrimination between the components caused by the failures at the different bearings, as well as monitoring of their severities.

\subsection{Computation of fault indicators.}

A fault severity indicator was defined to determine the level of bearing failure at each monitored interval. This indicator enables to observe if the considered fault component gets worse in the corresponding bearing or if, on the contrary, its amplitude remains stable.

Although there are many alternative fault indicators that may be defined based on the results of the time-frequency transforms, in this particular work we consider the fault index given by (7) that relates the energy of the time-frequency region containing the fault component (STFT_FC, denominator of the quotient in (7)) with the energy of the time-frequency region containing the main vibration component at the initial interval T4 (STFT_MC, numerator of the quotient in (7)). 
Note that, rather than an absolute threshold for determining if the fault is present or not, the main objective when defining this indicator is to observe how the fault degrades over time.

$$
\gamma_{H F}(d B)=10 \cdot \log \left[\frac{\sum_{i=N 0 t}^{N f t} \sum_{j=N 0 F}^{N f F} S T F T_{-} M C_{i, j}^{2}}{\sum_{i=N 0 t}^{N f t} \sum_{j=N 0 f}^{N f f} S T F T_{-} F C_{i, j}^{2}}\right]
$$

In (7), STFT_FC ${ }_{i, j}$ is the STFT value at a certain point $(i, j)$ of the time-frequency region that includes the considered fault component and $S T F T_{-} F C_{i, j}$ is the STFT value at a certain point $(i, j)$ of the time-frequency region containing the main vibration component at the initial time interval T4; $N_{0 t}$ and $N_{f t}$ are the initial and final time coordinates of the considered time interval (T4, T14 or T25 in this work); $N_{O f}$ and $N_{f f}$ are the initial and final coordinates defining the frequency interval of the t-f region containing the fault component; finally and $N_{O F}$ and $N_{f F}$ are the initial and final coordinates defining the frequency interval of the t-f region containing the main vibration component at the initial time interval.

Table III shows the computation of the fault indicator (last column) for both considered bearings (SKF 6204 and SKF 6202) at the different time intervals and at each measurement point (2, 3, 4 and 5). This table is referred to the component associated to a failure in the outer raceway of each bearing ( $f_{O}$ in Table II). Fig. 16 shows the graphic representation of the evolution of the indicator over the time (T4-T14-T25) at the different measurement points for the SKF 6204 bearing, based on the values of Table III. Interestingly, note that measurements at points 2, 4 and 5 reveal that the outer raceway failure gets worse over time (i.e. the value of the indicator successively decreases). This is logical since this is the bearing where the bearing currents were injected and, consequently, where the outer raceway is progressively damaged. Hence, this figure ratifies the information provided by the visual interpretation of the time-frequency maps at the previous sections and confirms the validity of the 
time-frequency analysis to see how the bearing currents increase the damage of the bearing outer raceway over time. Note that (unlike what happens at points 2, 4 and 5) at point 3 the indicator remains approximately stable. This is logical since this measurement point is much farther from the bearing where the fault takes place (see Fig. 7).

On the other hand, Fig. 17 is equivalent but for the SKF 6202 bearing. Note that the value of the indicator associated to the outer raceway failure in that bearing remains approximately stable. This is coherent with the time-frequency maps depicted in previous sections and shows how the level of failure in the outer raceway of this bearing does not substantially vary over the considered time intervals.

Finally, Table IV shows the values of the fault indicator (last column) for both considered bearings (SKF 6204 and SKF 6202) at the subsequent time intervals T4, T14 and at each measurement point (2, 3, 4 and 5). Unlike Table III, Table IV corresponds to the respective components associated to a failure in the bearing inner raceway ( $f_{I}$ in Table II). Fig. 18 shows the graphic representation of the evolution of the indicator over the time (T4-T14) at the different measurement points for the SKF 6204 bearing, based on the values of Table IV. Note that the measurements at all points remain approximately stable, a fact that shows that this particular failure does not get worse in this bearing (note that this is the bearing where the currents are injected). On the other hand, Fig. 19 is equivalent but for the SKF 6202 bearing. Unlike the previous figure, note that the value of the indicator associated to the inner raceway failure in bearing SKF 6202 progressively decreases over time at all measurement points; this indicates that the level of inner raceway failure progressively increases in that particular bearing This is coherent with the time-frequency maps depicted in previous sections that showed that the level of failure in the inner raceway of this bearing increased over time. 
Table III. Values of the fault indicator for each bearing at each measurement point considering the fault frequency $f_{O}$ (outer raceway damage)

\begin{tabular}{|c|c|c|c|c|}
\hline POINT & Bearing & Fault Frequency & Interval & Indicator (dB) \\
\hline \multirow[t]{3}{*}{2} & \multirow[t]{3}{*}{ SKF 6204} & \multirow[t]{3}{*}{$f_{O}(\sim 155 \mathrm{~Hz})$} & $\mathrm{T} 4$ & 22,05 \\
\hline & & & T14 & 17,26 \\
\hline & & & $\mathrm{T} 25$ & 11,07 \\
\hline \multirow[t]{3}{*}{2} & \multirow[t]{3}{*}{ SKF 6202} & \multirow[t]{3}{*}{$f_{O}(\sim 151 \mathrm{~Hz})$} & $\mathrm{T} 4$ & 35,43 \\
\hline & & & T14 & 29,07 \\
\hline & & & T25 & 34,78 \\
\hline \multirow[t]{3}{*}{4} & \multirow[t]{3}{*}{ SKF 6204} & \multirow[t]{3}{*}{$f_{O}(\sim 155 \mathrm{~Hz})$} & $\mathrm{T} 4$ & 30,90 \\
\hline & & & T14 & 27,01 \\
\hline & & & $\mathrm{T} 25$ & 10,87 \\
\hline \multirow[t]{3}{*}{4} & \multirow[t]{3}{*}{ SKF 6202} & \multirow[t]{3}{*}{$f_{O}(\sim 151 \mathrm{~Hz})$} & T4 & 20,63 \\
\hline & & & T14 & 17,84 \\
\hline & & & $\mathrm{T} 25$ & 23,35 \\
\hline \multirow[t]{3}{*}{5} & \multirow[t]{3}{*}{ SKF 6204} & \multirow[t]{3}{*}{$f_{O}(\sim 155 \mathrm{~Hz})$} & $\mathrm{T} 4$ & 3,87 \\
\hline & & & T14 & $-4,89$ \\
\hline & & & $\mathrm{T} 25$ & $-14,01$ \\
\hline \multirow[t]{3}{*}{5} & \multirow{3}{*}{ SKF 6202} & \multirow{3}{*}{$f_{O}(\sim 151 \mathrm{~Hz})$} & $\mathrm{T} 4$ & 8,67 \\
\hline & & & T14 & 2,25 \\
\hline & & & $\mathrm{T} 25$ & 8,29 \\
\hline \multirow[t]{3}{*}{3} & \multirow[t]{3}{*}{ SKF 6204} & \multirow[t]{3}{*}{$f_{o}(\sim 155 \mathrm{~Hz})$} & $\mathrm{T} 4$ & 47,25 \\
\hline & & & T14 & 38,73 \\
\hline & & & $\mathrm{T} 25$ & 41,45 \\
\hline \multirow[t]{3}{*}{3} & \multirow[t]{3}{*}{ SKF 6202} & \multirow[t]{3}{*}{$f_{O}(\sim 151 \mathrm{~Hz})$} & $\mathrm{T} 4$ & 42,00 \\
\hline & & & T14 & 33,66 \\
\hline & & & $\mathrm{T} 25$ & 39,72 \\
\hline
\end{tabular}


Fig. 20 shows some pictures obtained after disassembling the SKF6204 bearing after the tests. It can be observed the faulty condition of the outer cage provoked by the prolonged injection of currents; indeed, the pictures reveal the characteristic surface roughness pattern caused by this failure. On the other hand, the pictures reveal a slight level of failure in the inner raceway. These pictures prove that the information obtained with the time-frequency tools combined with the fault indicator provide a correct diagnostic of the condition of the bearing in the event of circulating bearing currents.

Table IV. Values of the fault indicator for each bearing at each measurement point considering the fault frequency $f_{I}$ (inner raceway damage)

\begin{tabular}{|c|c|c|c|c|}
\hline POINT & Bearing & Fault Frequency & Interval & Indicator (dB) \\
\hline \multirow[t]{2}{*}{2} & \multirow[t]{2}{*}{ SKF 6204} & \multirow[t]{2}{*}{$f_{I}(\sim 247 \mathrm{~Hz})$} & T4 & 40,72 \\
\hline & & & T14 & 37,31 \\
\hline \multirow[t]{2}{*}{2} & \multirow[t]{2}{*}{ SKF 6202} & \multirow[t]{2}{*}{$f_{I}(\sim 251 \mathrm{~Hz})$} & T4 & 40,61 \\
\hline & & & T14 & 30,47 \\
\hline \multirow[t]{2}{*}{4} & \multirow[t]{2}{*}{ SKF 6204} & \multirow[t]{2}{*}{$f_{I}(\sim 247 \mathrm{~Hz})$} & T4 & 44,13 \\
\hline & & & T14 & 48,15 \\
\hline \multirow[t]{2}{*}{4} & \multirow[t]{2}{*}{ SKF 6202} & \multirow[t]{2}{*}{$f_{I}(\sim 251 \mathrm{~Hz})$} & T4 & 46,10 \\
\hline & & & T14 & 30,93 \\
\hline \multirow[t]{2}{*}{5} & \multirow[t]{2}{*}{ SKF 6204} & \multirow[t]{2}{*}{$f_{I}(\sim 247 \mathrm{~Hz})$} & T4 & 9,13 \\
\hline & & & T14 & $\mathbf{9 , 8 8}$ \\
\hline \multirow[t]{2}{*}{5} & \multirow[t]{2}{*}{ SKF 6202} & \multirow[t]{2}{*}{$f_{I}(\sim 251 \mathrm{~Hz})$} & T4 & 13,93 \\
\hline & & & T14 & 9,33 \\
\hline \multirow[t]{2}{*}{3} & \multirow[t]{2}{*}{ SKF 6204} & \multirow[t]{2}{*}{$f_{I}(\sim 247 \mathrm{~Hz})$} & T4 & 55,69 \\
\hline & & & T14 & 53,88 \\
\hline \multirow[t]{2}{*}{3} & \multirow[t]{2}{*}{ SKF 6202} & \multirow[t]{2}{*}{$f_{I}(\sim 251 \mathrm{~Hz})$} & T4 & 49,05 \\
\hline & & & T14 & 32,63 \\
\hline
\end{tabular}




\section{CONCLUSIONS}

In the present paper, the application of time-frequency analysis of vibration data has been proposed for monitoring bearing damages provoked by circulating bearing currents. This type of failure is of special interest for industrial users due to its frequent occurrence in applications involving inverted-fed motors. Until now, no satisfactory solution has been found to overcome this problem or, at least, to reliably monitor the bearing degradation caused by this fault. The experimental results included in the paper, developed with an innovative test bench, have proven that time-frequency analysis of machine quantities as vibration data may be a powerful source of information due to its significant advantages, namely:

- Possibility of continuous tracking of the amplitude of components associated with different bearing failures, a fact that enables to monitor the evolution of the corresponding fault severity.

- Possible application even under non-stationary conditions, which may be especially useful in motors involved in applications where the load continuously change or with frequent start-stop cycles.

- Better discrimination among components associated to simultaneous failures in different bearings that are plotted as separate evolutions in the resulting time-frequency map.

- Robust discrimination versus other components related to other failures in the machine (e.g., rotor faults, eccentricities), since the time-frequency evolutions of the fault components are less likely to overlap than their respective frequencies in an FFT spectrum.

- Facility of introducing fault severity indicators based on the time-frequency information obtained with these signal processing tools.

All these advantages confer a great potential for the possible implementation of these tools in on-line condition monitoring systems or portable devices that are intended to diagnose the deterioration of bearing damages due to bearing currents. 
Finally, the innovative test bed developed in this work will also enable the future assessment of tests methods for the diagnostic or prognostic of damages provoked by bearing currents.

The approach presented in this work will be extended in future works to the detection of the considered fault by means of analysis of currents rather than vibrations. In this sense, the analysis of this quantity may provide certain advantages as the avoidance of vibration sensors installation in the machine and may be an excellent complementary informational source for the diagnosis of the bearing damages.

\section{ACKNOWLEDGMENT}

This work was supported in part by IPES (which is a joint research laboratory between the Laboratory Ampère and Safran) and in part by the Spanish 'Ministerio de Economía y Competitividad' (MINECO) and FEDER program in the framework of the 'Proyectos I+D del Subprograma de Generación de Conocimiento, Programa Estatal de Fomento de la Investigación Científica y Técnica de Excelencia' (ref: DPI2014-52842-P).”

\section{REFERENCES}

[1] D. Macdonald and W. Gray, "A Practical Guide to Understanding Bearing Damage Related to PWM Drives", in Conference Record of the 1998 Pulp and Paper Industry Technical Committee (PPIC 1998), Portland, USA, pp. 159-165.

[2] ABB, "Bearing Currents in AC drive systems" ABB technical notes, www.abb.com/drives, 2011.

[3] A. Muetze, "Bearing Currents in Inverter-Fed AC-Motors", Diploma Thesis in Electrical and Computer Engineering. Technischen Universitaet Darmstadt.

http://www.ew.tu-darmstadt.de/media/ew/dissertationen/dissannette.pdf. 
[4] D. Dahl, D. Sosnowski, D. Schlegel, R.J. Kerkman and M. Pennings, "Gear up your Bearings: A field case study on bearing damage in low voltage ac induction motors", IEEE Industry Applications Magazine, July/Aug 2008, pp.45-53.

[5] T. Heino, "Bearing Currents and Their Mitigation in Frequency Converter-driven Induction Motors," Bs. Thesis dissertation, Vaasa 2014.

[6] W. Oh, "Preventing VFD/AC Drive Induced Electrical Damage to AC Motor Bearings", Technical white paper. AEGIS bearing protection rings. September 2006, www.ets-aegis.com/Techpaper.pdf

[7] B. Dolenc, P.Boskosky and D. Juricic, "Distributed Bearing Fault Diagnosis based on Vibration Analysis”, Mechanical Systems and Signal Processing, Elsevier, Vol. 66-67, January 2016, pp. 531532

[8] E.P. Moura, C.R. Couto, A.A. Silva and M.A.S. Irmao, "Evaluation of Principal Component Analysis and Neural Network Performance for Bearing Fault Diagnosis from Vibration Signal Processed by RS and DF analyses," Mechanical Systems and Signal Processing, Elsevier, Vol. 25, No. 5, July 2011, pp. 1765-1772.

[9] M. Amar, I. Gondal and C. Wilson, "Vibration Spectrum Imaging: A Novel Bearing Fault Classification Approach", IEEE Transactions on Industrial Electronics, Vol. 62, No. 1, January 2015, pp 494-502.

[10] S. Singh, C.Q. Howard, C.H.Hansen, "An Extensive Review of Vibration Modelling of Rolling Element Bearings with Localised and Extended Defects", Journal of Sound and Vibration, Elsevier, Vol. 357, November 2015, pp. 300-330.

[11] J. Antonino-Daviu M. Riera-Guasp, J. Roger-Folch and M.P. Molina, "Validation of a New Method for the Diagnosis of Rotor bar Failures via Wavelet Transformation in Industrial Induction Machines," IEEE Transactions on Industry Applications., Vol. 42, No. 4, pp. 990-996, July/August 2006. 
[12] R.R. Schoen, T.G. Habetler, "Evaluation and Implementation of a System to Eliminate Arbitrary Load Effects in Current-Based Monitoring of Induction Machines", IEEE Transactions on Industry Applications, Vol. 33, No. 6, November/December 1997, pp. 1571-1577.

[13] C. Yang, T-J. Kang, D. Hyun, S. Lee, J. Antonino-Daviu, J. Pons-Llinares, "Reliable Detection of Induction Motor Rotor Faults Under the Rotor Axial Air Duct Influence," IEEE Transactions on Industry Applications, vol. 50, no. 4, pp. 2493-2502, Jul.-Aug. 2014.

[14] S. Shin, J. Kim, S.B. Lee, C. Lim, E. Wiedenbrug, "Evaluation of the influence of rotor magnetic anisotropy on condition monitoring of 2 pole induction motors," Proc. IEEE ECCE, Pittsburgh, USA, pp. 638-645, Sept. 2014.

[15] J. Antonino-Daviu,V. Climente-Alarcon, J. Pons-Llinares and E. Wiedenbrug, "Advanced rotor assessment of motors operating under variable load conditions in mining facilities," Proc. IEEE ECCE, Pittsburgh, USA, pp. 617-621, Sep 2014.

[16] J. Antonino-Daviu, P. Jover, M. Riera-Guasp, J. Roger-Folch and A. Arkkio, "DWT Analysis of Numerical and Experimental Data for the Diagnosis of Dynamic Eccentricities in Induction Motors”, Mechanical Systems and Signal Processing, Elsevier, Vol. 21, No. 6, August 2007, pp. 2575-2589.

[17] Z. Zhang and Z. Ren, "A novel detection method of motor broken rotor bars based on wavelet ridge," IEEE Transactions on Energy Conversion, Vol. 18, No. 3 September 2003, pp. 417-423..

[18] V.K. Rai and A.R. Mohanty, "Bearing Fault diagnosis using FFT of intrinsic mode functions in Hilbert-Huang transform”, Mechanical Systems and Signal Processing, Elsevier, Vol. 21, No. 6, August 2007, pp. 2607-2615.

[19] D. Yu, J. Cheng and Y. Yang, "Application of EMD method and Hilbert spectrum to the fault diagnosis of roller bearings", Mechanical Systems and Signal Processing, Elsevier, Vol. 19, 2005, pp. 258-270. 
[20] W. He, Y. Zi, B. Chen, F. Wu and Z. He, "Automatic Fault Feature Extration of Mechanical Anomaly on Induction Motor Bearing using Ensemble Super-Wavelet Transform”, Mechanical Systems and Signal Processing, Elsevier, Vol. 54-55, March 2015, pp. 457-480.

[21] Z.K. Peng, P.W. Tse, F.L. Chu, “A Comparison Study of Improved Hilbert-Huang Transform and Wavelet Transform: Application to Fault Diagnosis for Rolling Bearing”, Mechanical Systems and Signal Processing, Elsevier, Vol. 19, 2005, pp. 974-988.

[22] J. Zarei and J. Poshtan, "Bearing Fault Detection using Wavelet Packet Transform of Induction Motor Stator Current”, Tribology International, Elsevier, No. 40, 2007, pp. 763-769.

[23] F. Immovilli, M. Cocconcelli, A. Bellini and R. Rubini, "Detection of Generalized-Roughness Bearing Fault by Spectral-Kurtosis Energy of Vibration or Current Signals", IEEE Transactions on Industrial Electronics, Vol. 56, No. 11, November 2009, pp 4710-4717.

[24] R.R. Schoen, T.G. Habetler, F. Kamran and R.G. Bartheld, "Motor Bearing Damage Detection Using Stator Current Monitoring”, IEEE Transactions on Industry Applications, Vol. 31, No. 6, November/December 1995, pp. 1274-1279.

[25] R. K. Singleton; E. G. Strangas; S. Aviyente, "Extended Kalman Filtering for Remaining-UsefulLife Estimation of Bearings," IEEE Transactions on Industrial Electronics, Vol. 62, No. 3, pp. 1781 - 1790, Mar. 2015.

[26] Z. Feng, M. Liang and F. Chu, "Recent advances in time-frequency analysis methods for machinery fault diagnosis: A review with application examples", Mechanical Systems and Signal Processing, Elsevier, Vol. 38, 2013, pp. 165-205.

[27] J. Pons-Llinares, J.A. Antonino-Daviu, M. Riera-Guasp, Sang Bin Lee, Tae-June Kang, Chanseung Yang, "Advanced Induction Motor Rotor Fault Diagnosis Via Continuous and Discrete Time-Frequency Tools," IEEE Transactions on Industrial Electronics, vol.62, no.3, pp. 1791-1802, Mar. 2015. 
[28] J. Pons-Llinares, V. Climente-Alarcón, F. Vedreño-Santos, J. Antonino-Daviu, and M. RieraGuasp, "Electric Machines Diagnosis Techniques via Transient Current Analysis," Proc. of IEEE IECON, Montreal, Canada, Nov. 2012.

[29] V. Climente-Alarcon, "Contributions to the predictive maintenance of induction motors by applying modern signal processing techniques”, PhD Thesis dissertation. Valencia, Spain, 2012. 


\section{List of figure captions}

Figure 1. Effects of bearing currents on a real bearing: (a) Surface roughness of a bearing race caused by fluting effect, (b) Matt-grey colour of bearing balls.

Figure 2. Schematic representation of the ball bearing characteristics used in expressions (1) to (4).

Figure 3. Pictures of the two bearings considered for the tests.

Figure 4. Schematic representation of the different types of time-frequency tools.

Figure 5. Scheme (top) and picture (bottom) of the experimental test bed.

Figure 6. Waveforms of the voltage applied between bearing cage and shaft (top) and resulting current pulses (bottom).

Figure 7. Detail of the vibration measurement points.

Figure 8. STFT analysis for the vibration signal at point 2 during the time intervals T4, T14 and T25 (frequency band $145-160 \mathrm{~Hz}$ ).

Figure 9. STFT analysis for the vibration signal at point 2 during the time intervals T4 and T14 (frequency band $245-254 \mathrm{~Hz}$ ).

Figure 10. STFT analysis for the vibration signal at point 4 during the time intervals T4, T14 and T25 (frequency band $145-160 \mathrm{~Hz}$ ).

Figure 11. STFT analysis for the vibration signal at point 4 during the time intervals T4 and T14 (frequency band 245-255 Hz).

Figure 12. STFT analysis for the vibration signal at point 5 during the time intervals T4, T14 and T25 (frequency band 145-160 Hz).

Figure 13. STFT analysis for the vibration signal at point 5 during the time intervals T4 and T14 (frequency band $245-254 \mathrm{~Hz}$ ). 
Figure 14. STFT analysis for the vibration signal at point 3 during the intervals T4, T14 and T25 (frequency band 145-160 Hz).

Figure 15. STFT analysis for the vibration signal at point 3 during the time intervals T4 and T14 (frequency band $245-254 \mathrm{~Hz}$ ).

Figure 16. Graphical representation of the evolution of the fault severity indicator at each measurement point for the bearing SKF 6204 (fault component $f_{O}$ (outer raceway damage)).

Figure 17. Graphical representation of the evolution of the fault severity indicator at each measurement point for the bearing SKF 6202 (fault component $f_{O}$ (outer raceway damage)).

Figure 18. Graphical representation of the evolution of the fault severity indicator at each measurement point for the bearing SKF 6204 (fault component $f_{I}$ (inner raceway damage)).

Figure 19. Graphical representation of the evolution of the fault severity indicator at each measurement point for the bearing SKF 6202 (fault component $f_{I}$ (inner raceway damage)).

Figure 20. Pictures of the bearing SKF 6204 after its disassembly: (a) Outer raceway; (b) Inner raceway. 


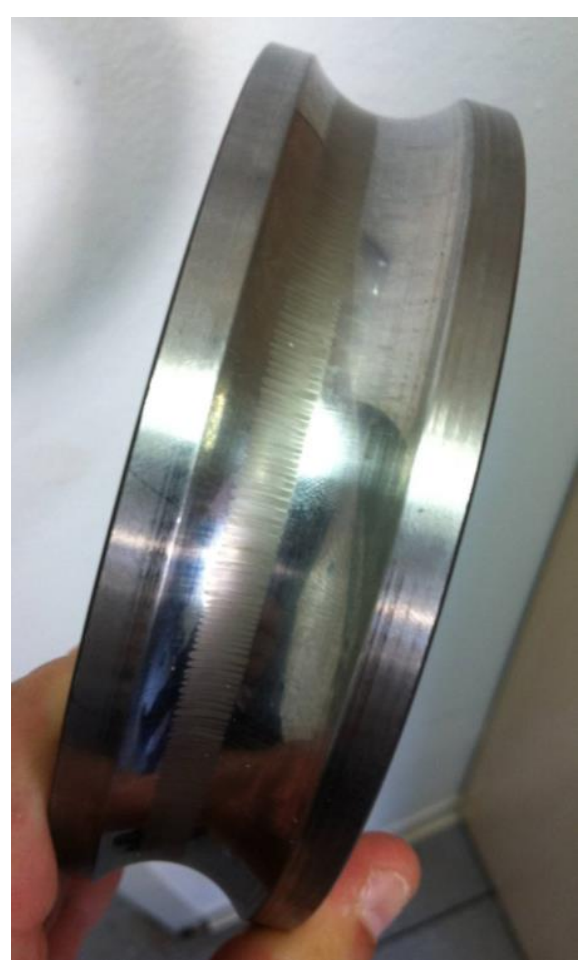

(a)

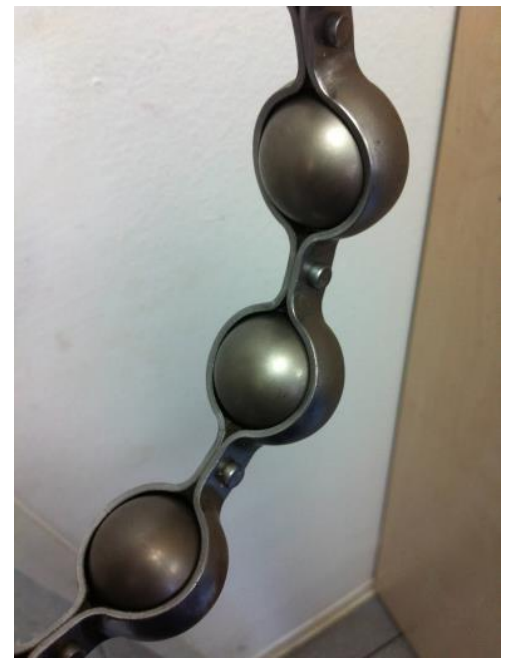

(b)

Figure 1. Effects of bearing currents on a real bearing: (a) Surface roughness of a bearing race caused by fluting effect, (b) Matt-grey colour of bearing balls.
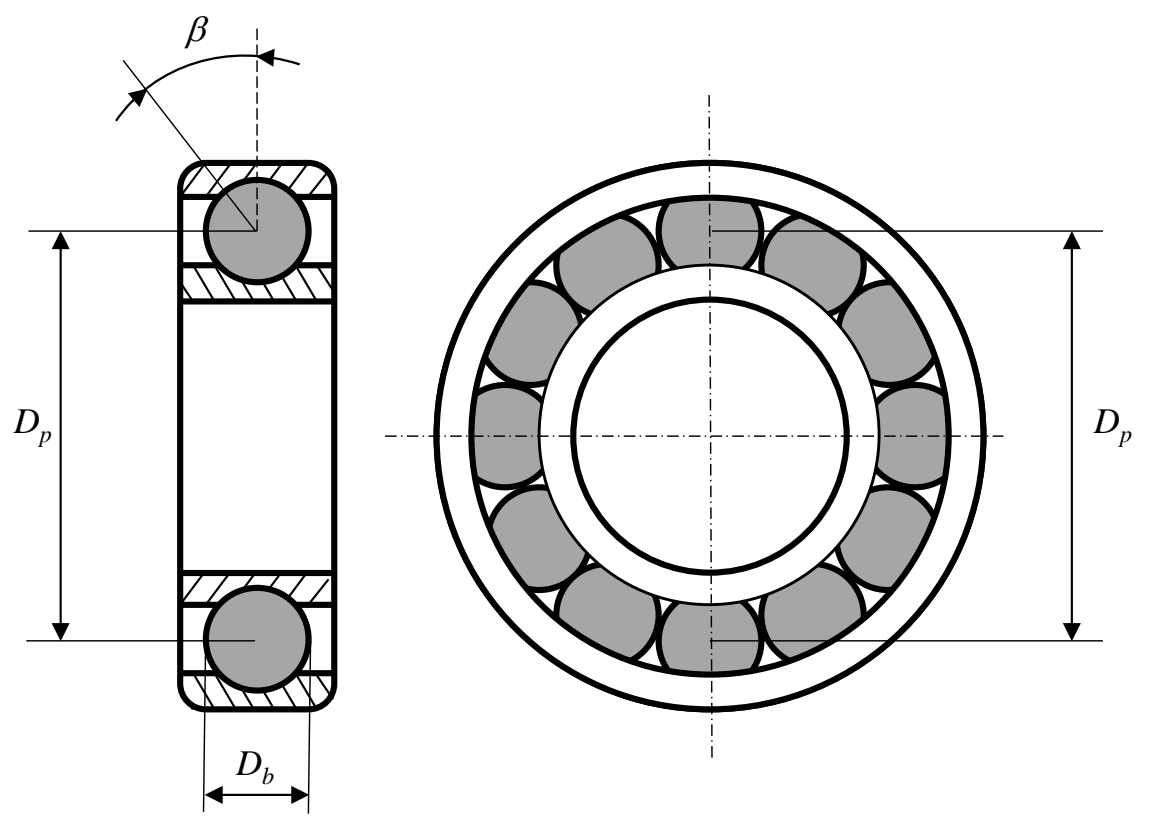

Figure 2. Schematic representation of the ball bearing characteristics used in expressions (1) to (4). 


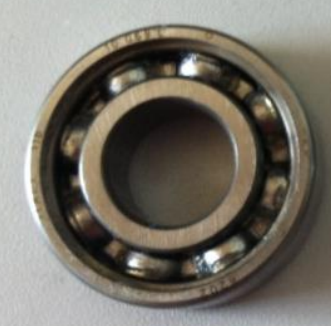

SKF Explorer 6202

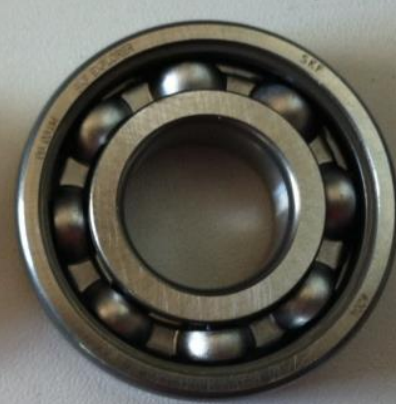

SKF Explorer 6204

Figure 3. Pictures of the two bearings considered for the tests.
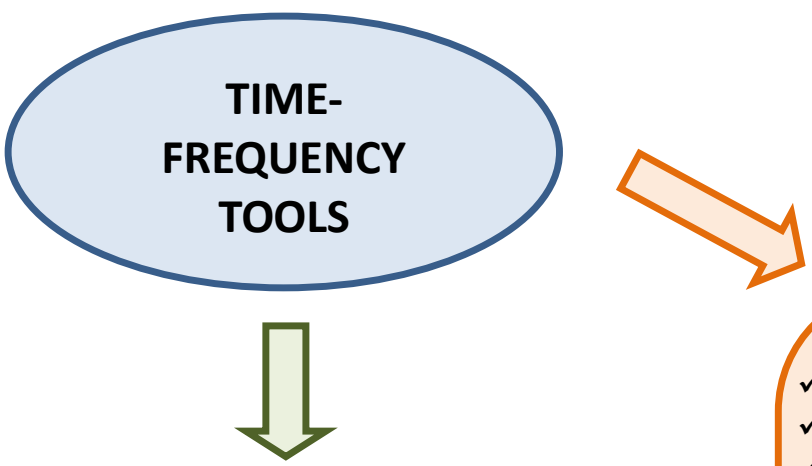

\section{CONTINUOUS}

More complete representation of the fault components evolutions.

$\checkmark \quad$ Enable the diagnostic based on more harmonics: higher reliability

$\checkmark \quad$ Enable the discrimination among failures and between failures and other phenomena

$\checkmark \quad$ Suitable for off-line diagnosis

$\checkmark \quad$ E.g: STFT, CWT, WVD
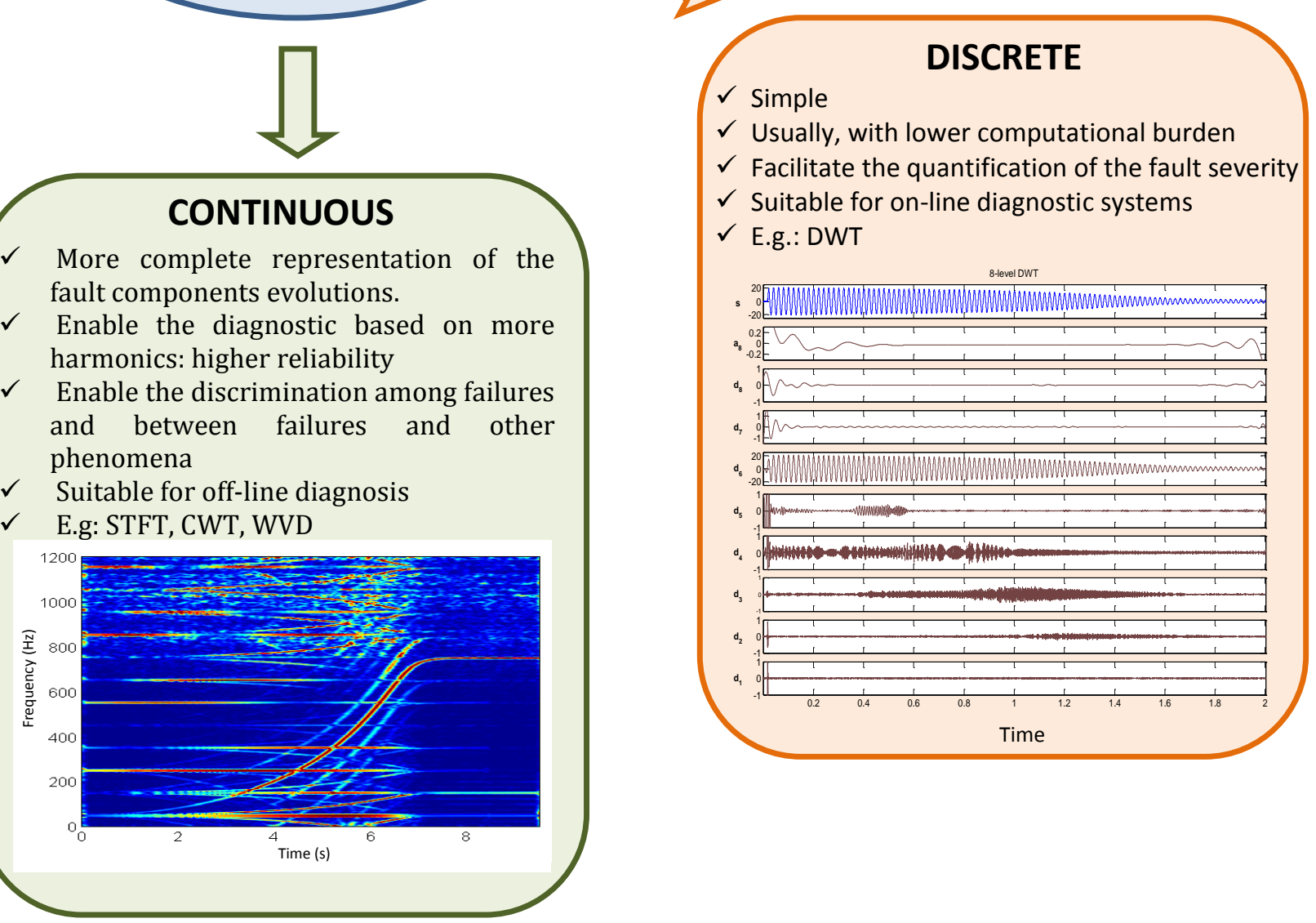

Figure 4. Schematic representation of the different types of time-frequency tools. 


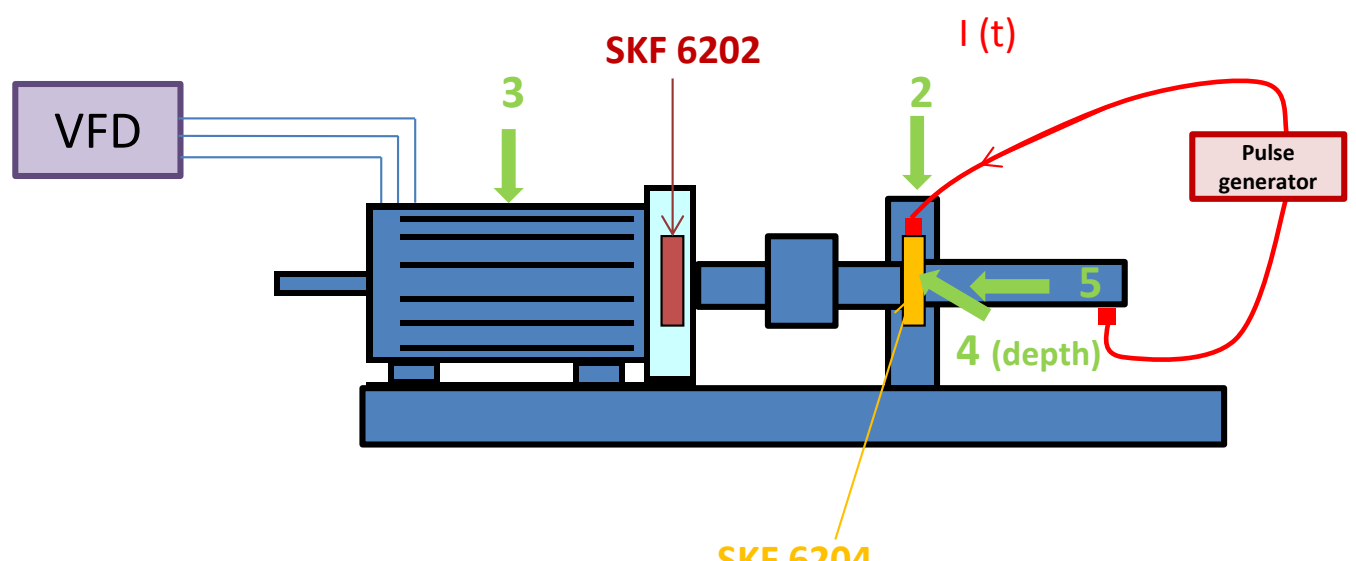

SKF 6204

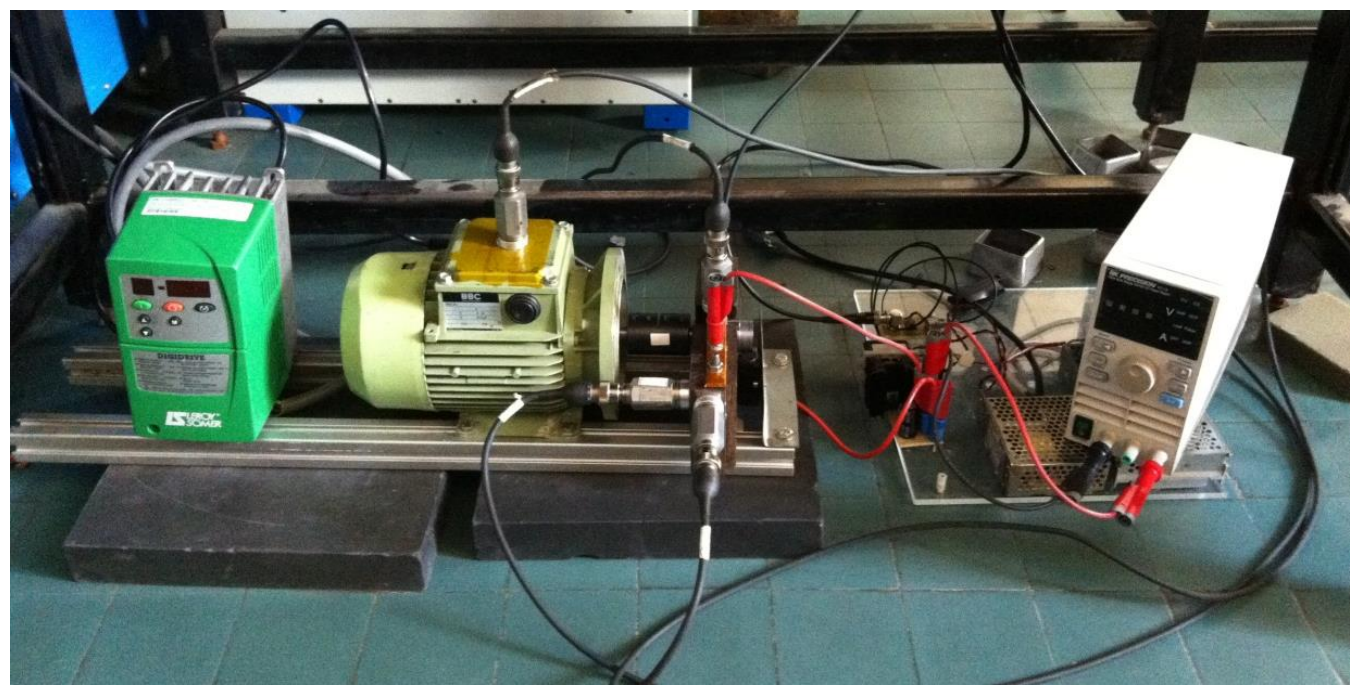

Figure 5. Scheme (top) and picture (bottom) of the experimental test bed. 


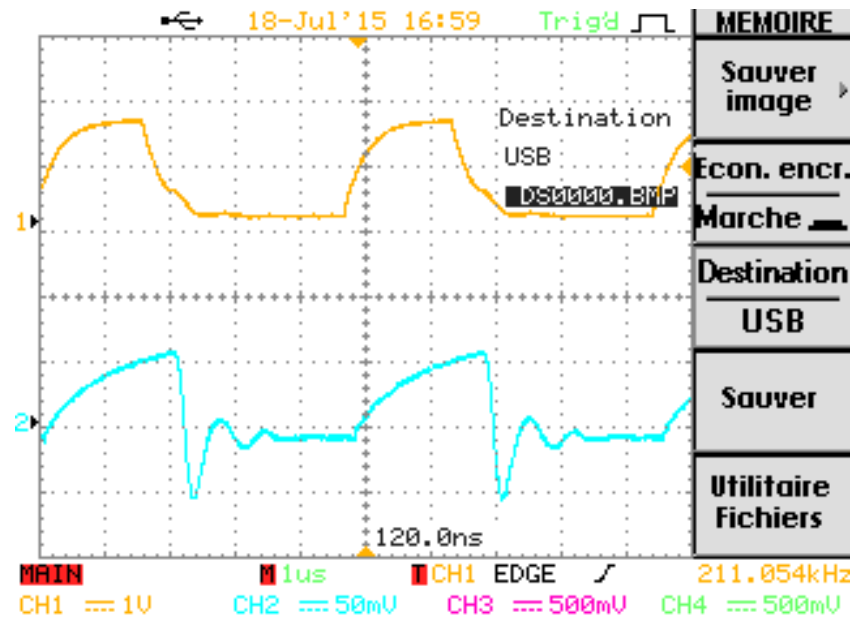

Figure 6. Waveforms of the voltage applied between bearing cage and shaft (top) and resulting current pulses (bottom).

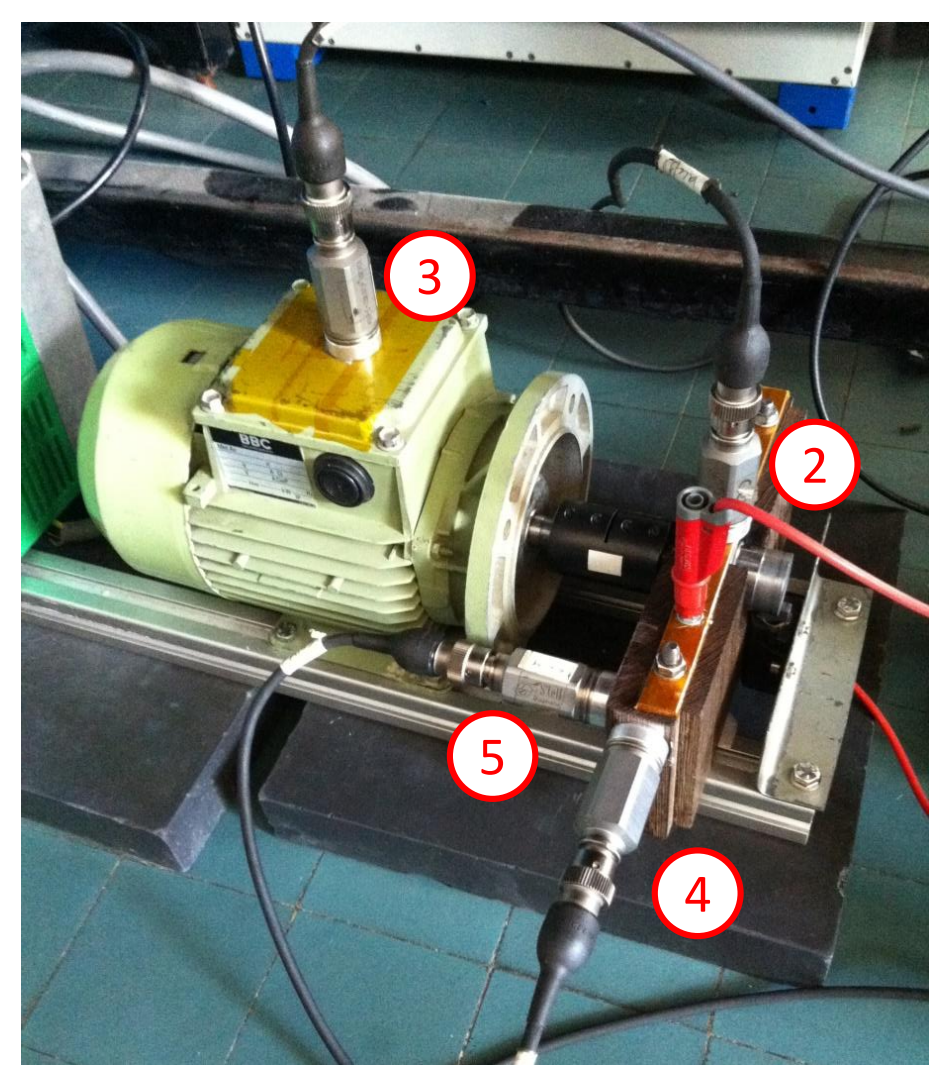

Figure 7. Detail of the vibration measurement points. 


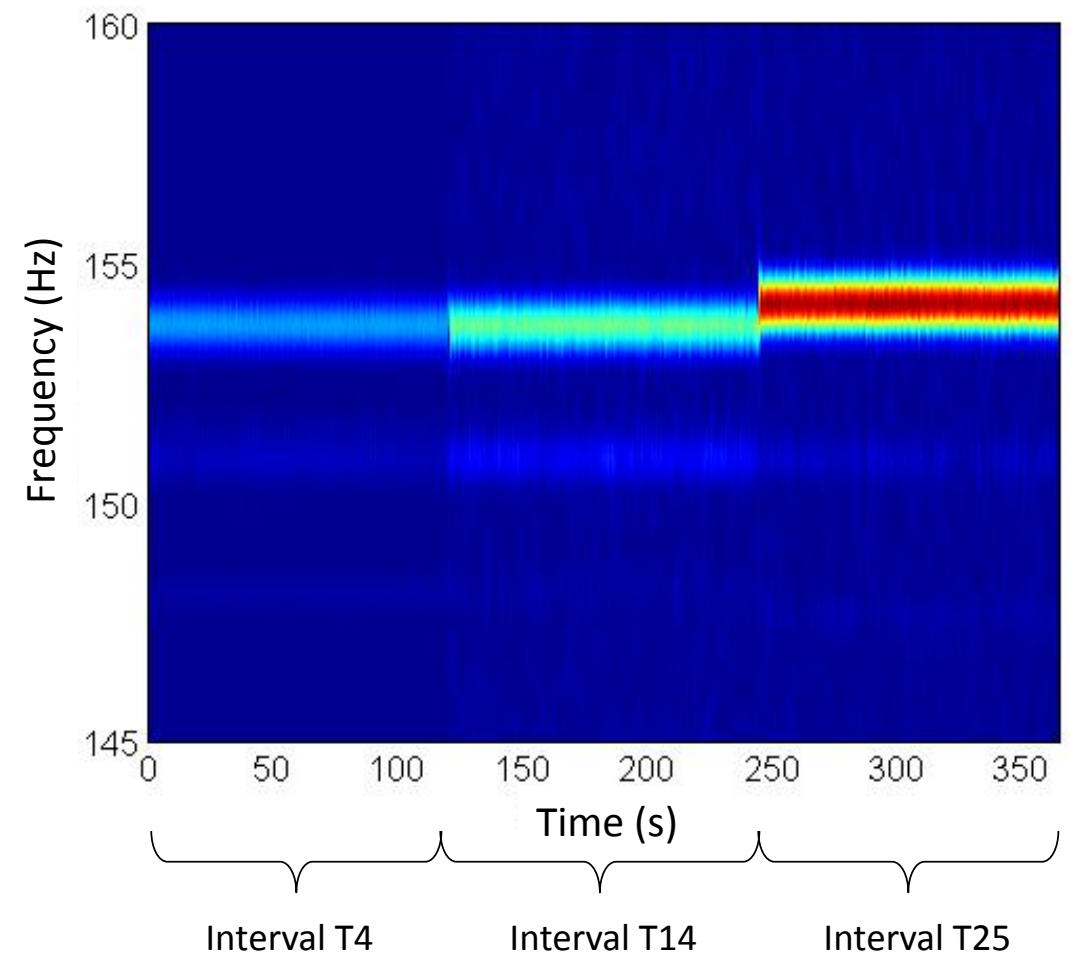

Figure 8. STFT analysis for the vibration signal at point 2 during the time intervals T4, T14 and T25 (frequency band 145-160 Hz).

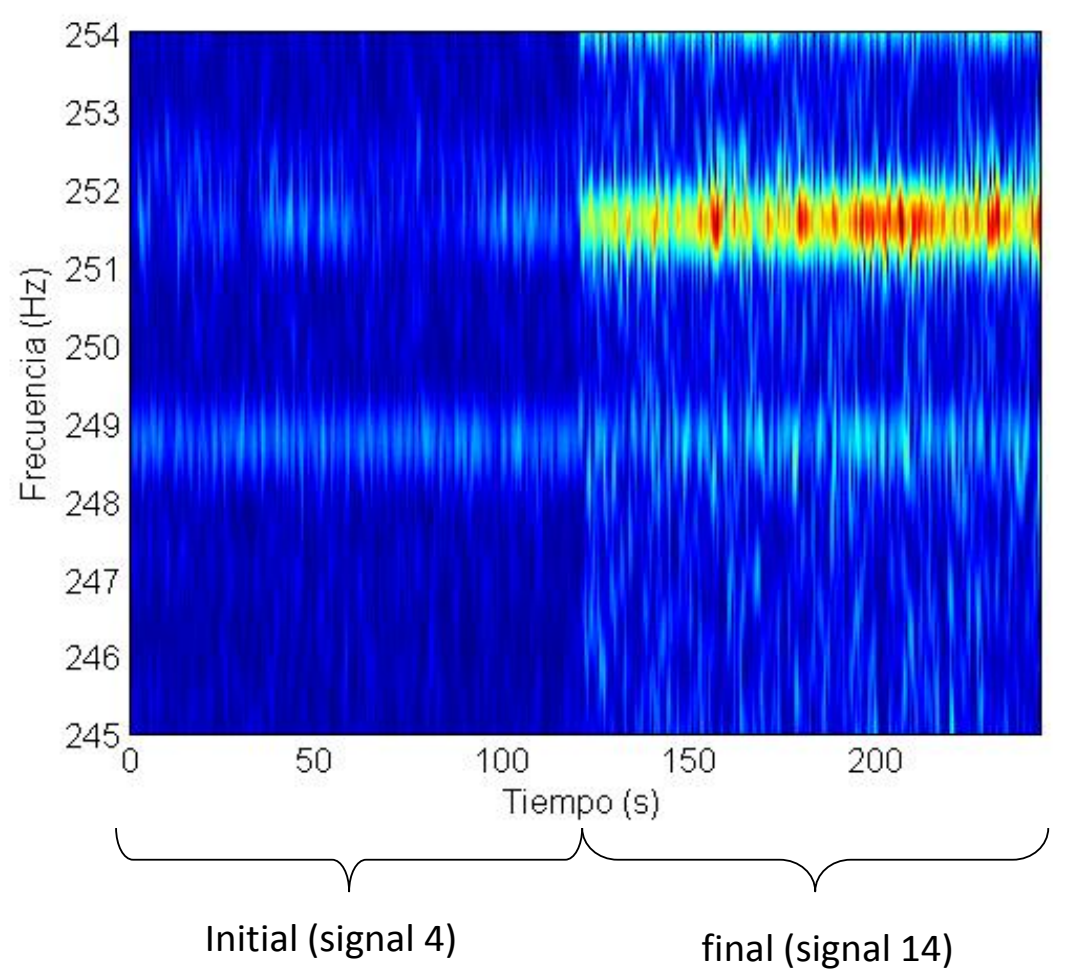

Figure 9. STFT analysis for the vibration signal at point 2 during the time intervals T4 and T14 (frequency band 245-254 Hz). 


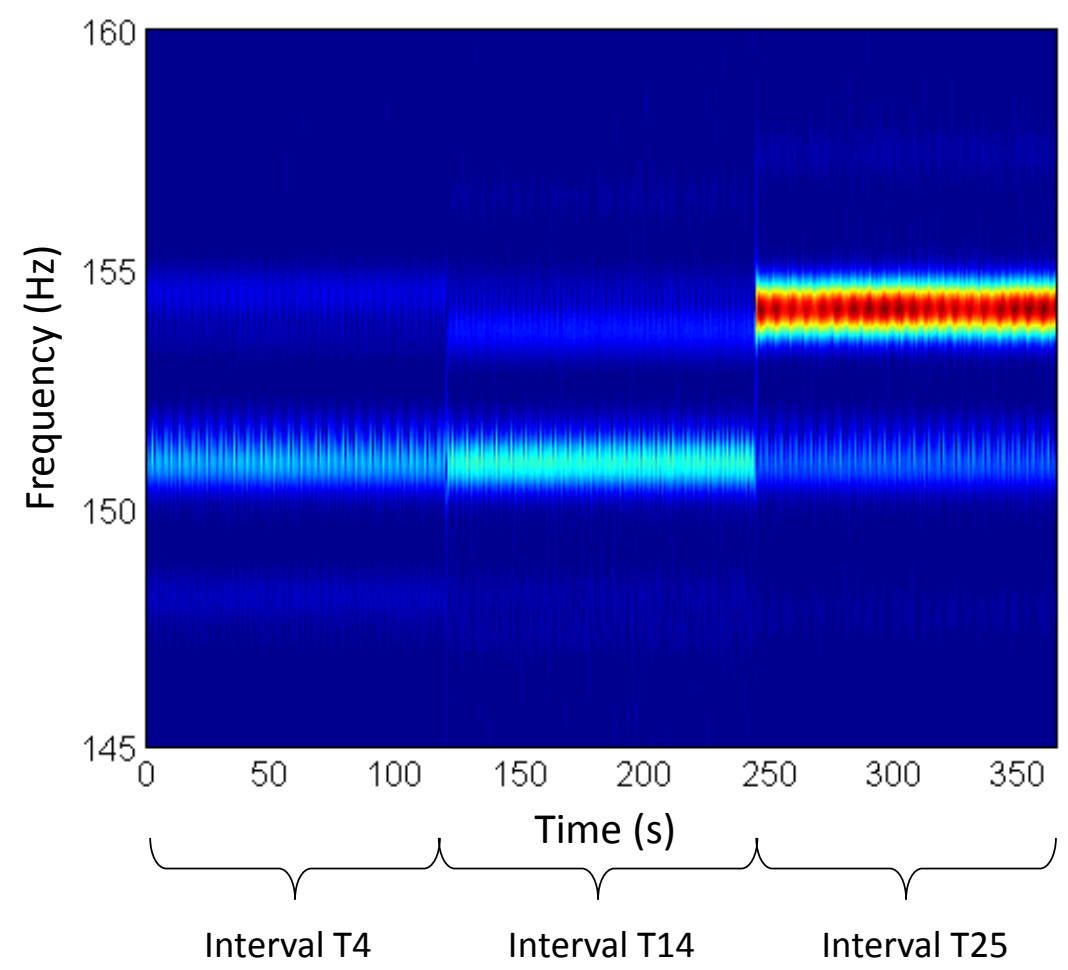

Figure 10. STFT analysis for the vibration signal at point 4 during the time intervals T4, T14 and T25 (frequency band $145-160 \mathrm{~Hz}$ ).

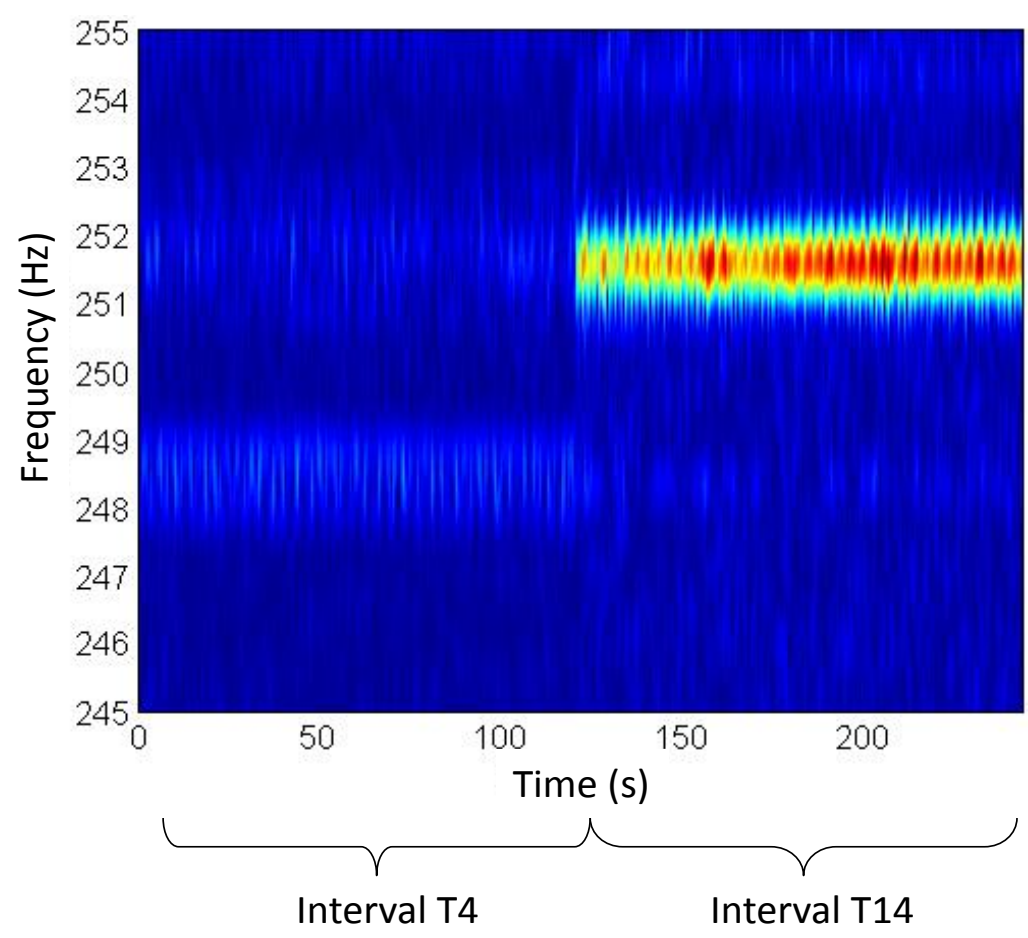

Figure 11. STFT analysis for the vibration signal at point 4 during the time intervals T4 and T14 (frequency band $245-255 \mathrm{~Hz}$ ). 


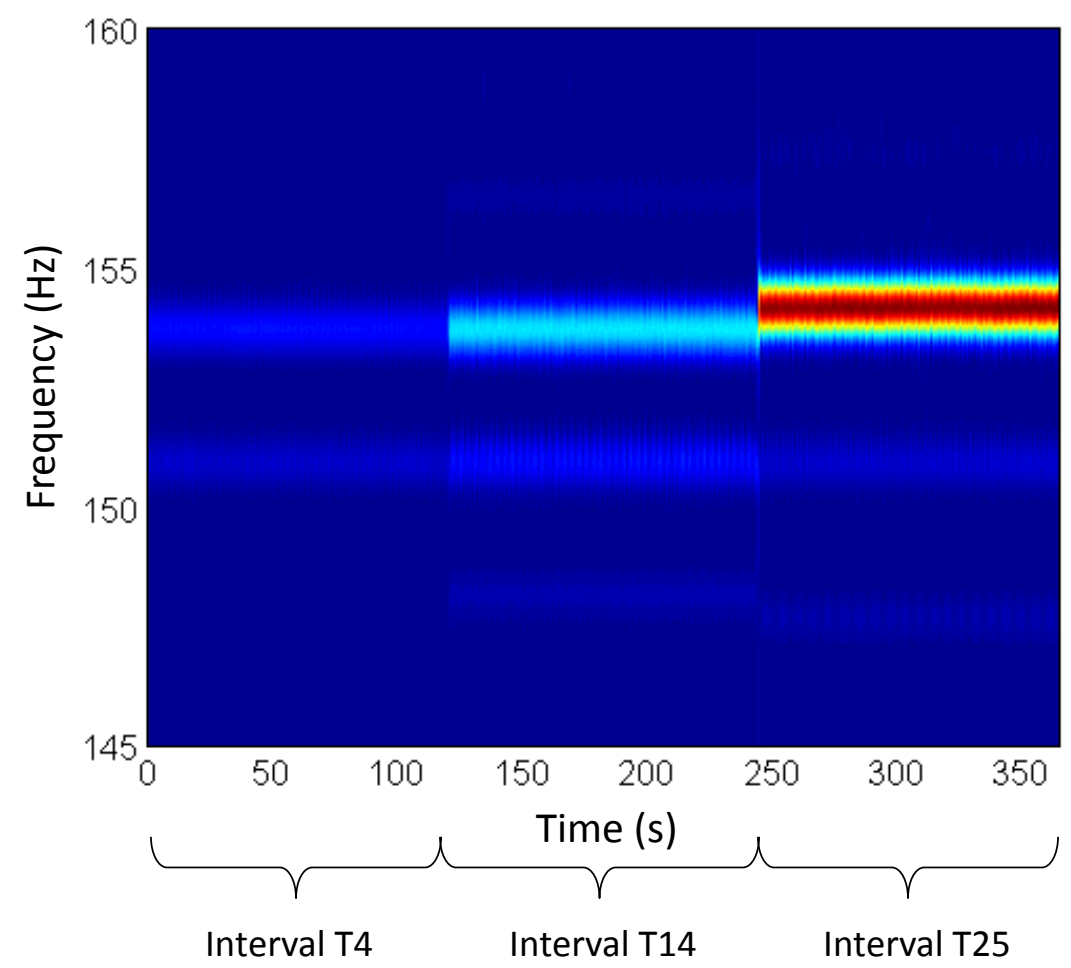

Figure 12. STFT analysis for the vibration signal at point 5 during the time intervals T4, T14 and T25 (frequency band 145-160 Hz).

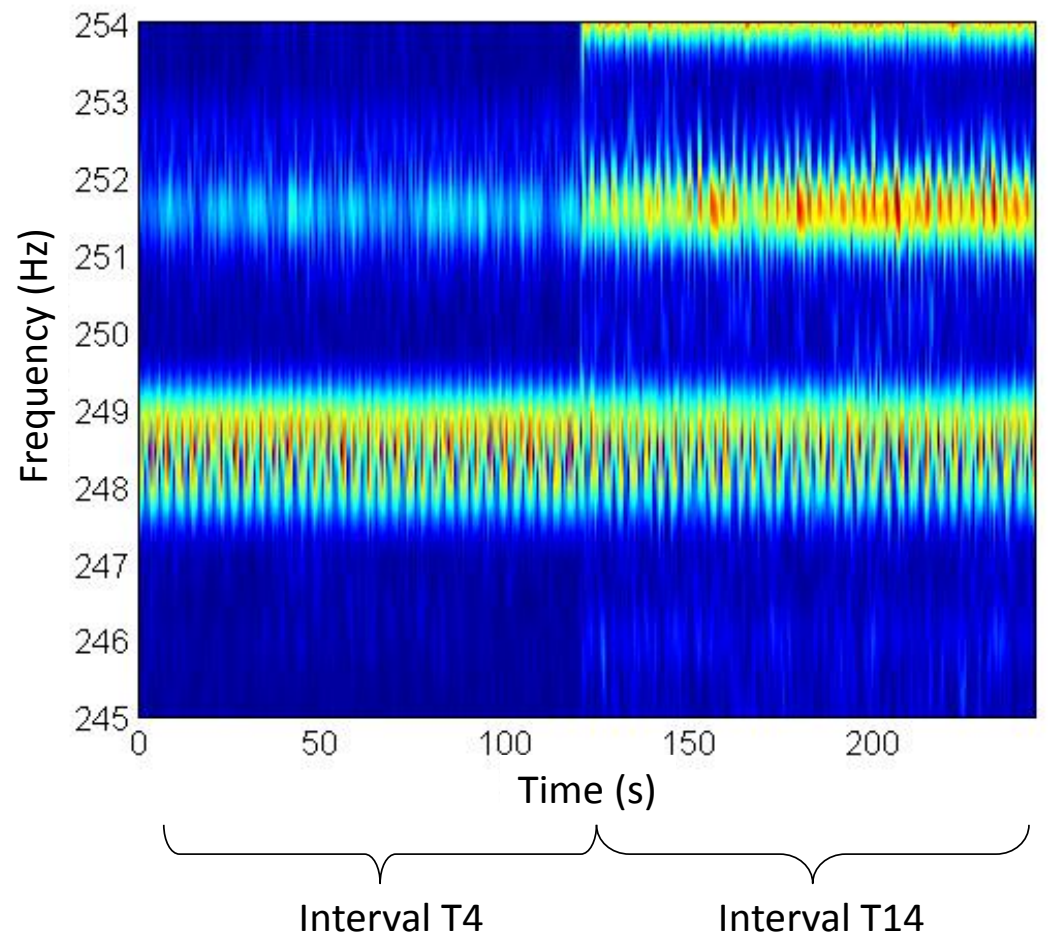

Figure 13. STFT analysis for the vibration signal at point 5 during the time intervals T4 and T14 (frequency band 245-254 Hz). 


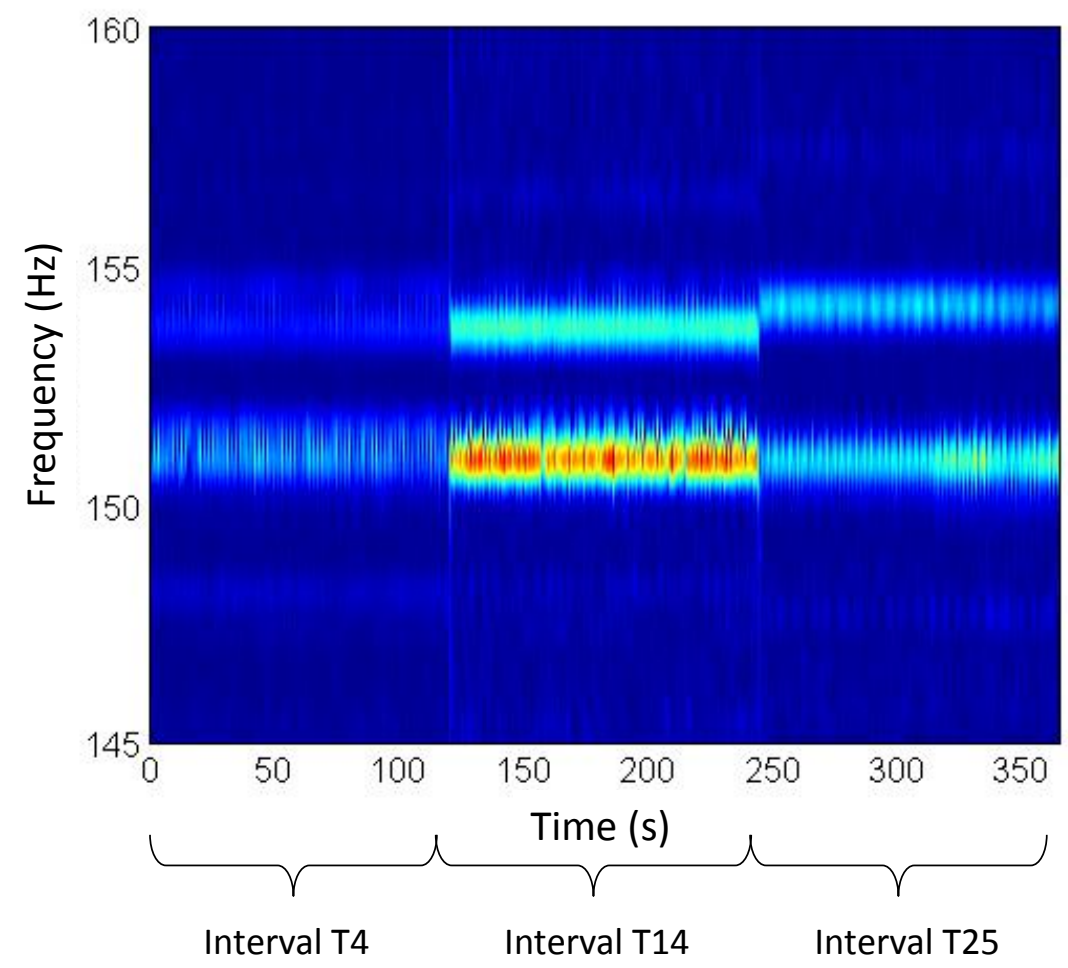

Figure 14. STFT analysis for the vibration signal at point 3 during the intervals T4, T14 and T25 (frequency band $145-160 \mathrm{~Hz}$ ).

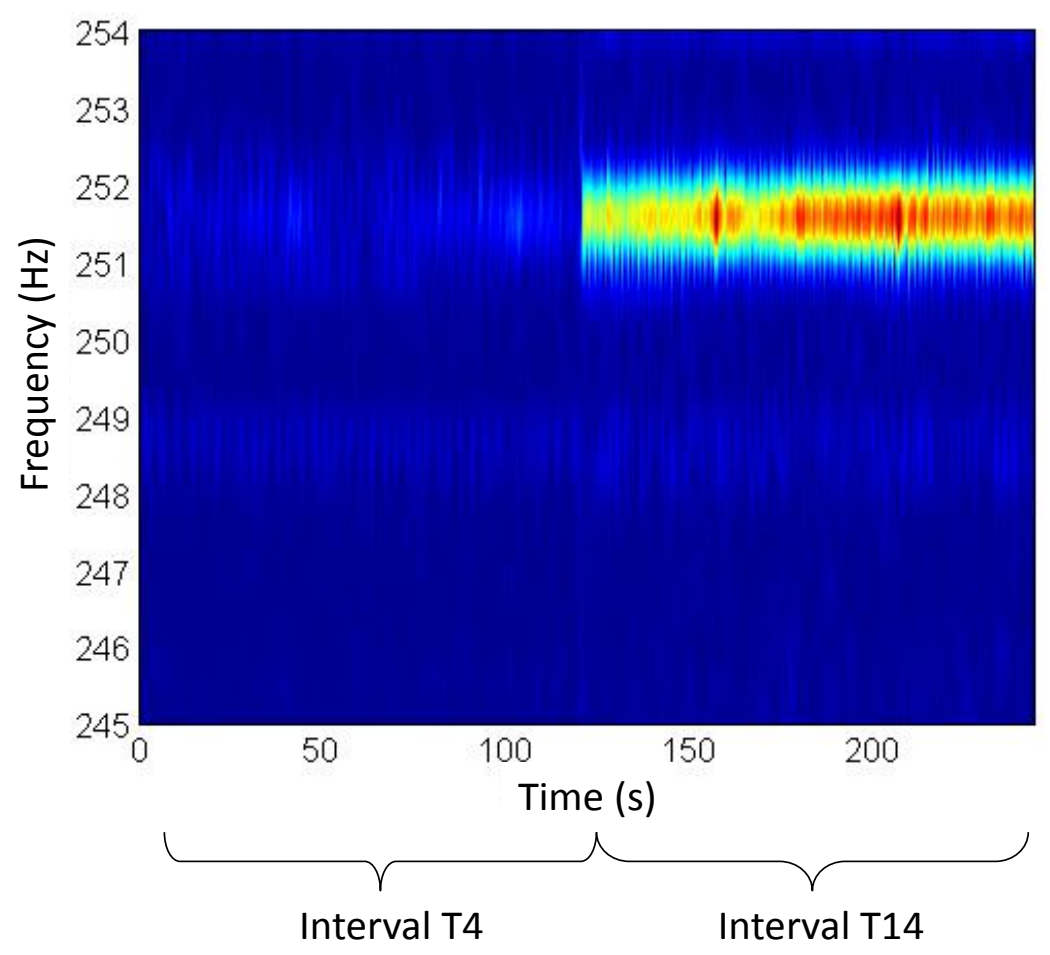

Figure 15. STFT analysis for the vibration signal at point 3 during the time intervals T4 and T14 (frequency band $245-254 \mathrm{~Hz}$ ). 


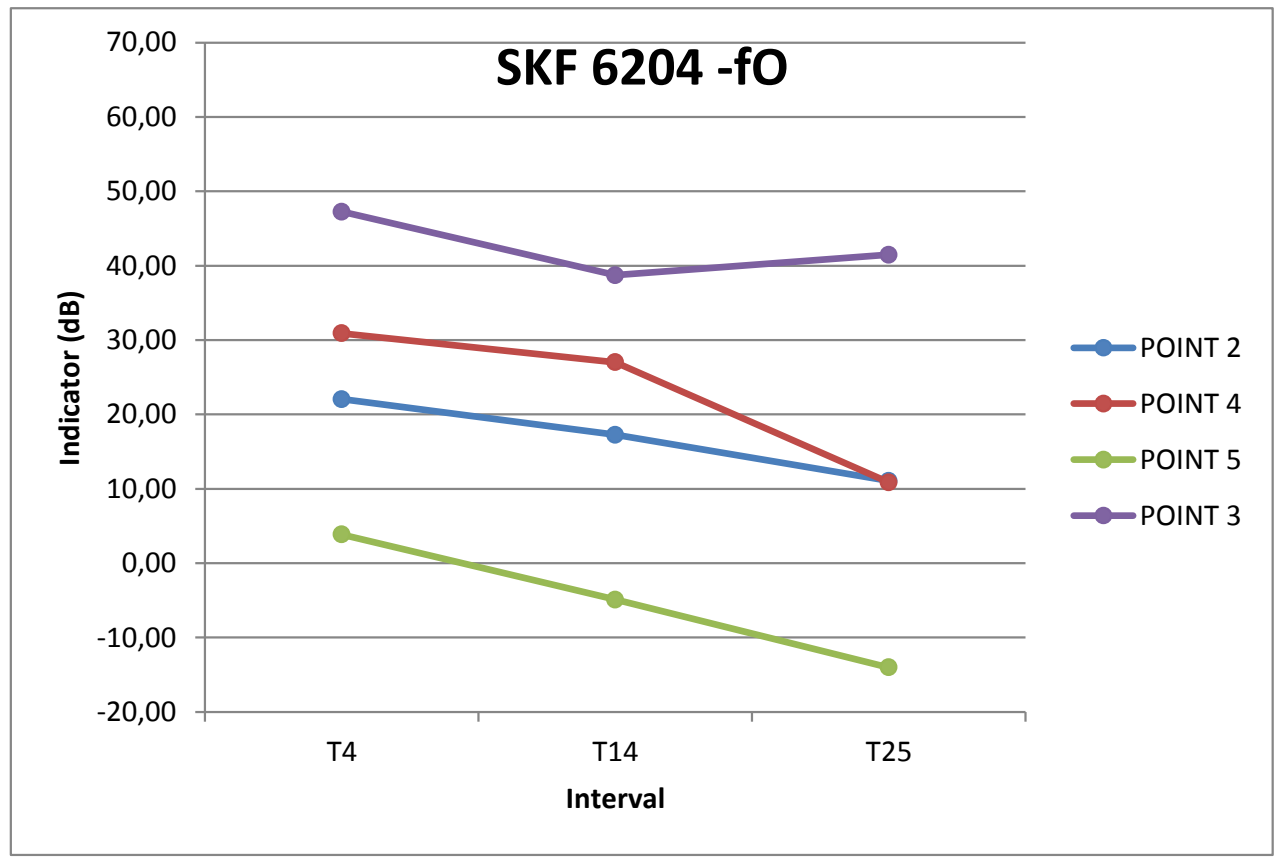

Figure 16. Graphical representation of the evolution of the fault severity indicator at each measurement point for the bearing SKF 6204 (fault component $f_{O}$ (outer raceway damage)).

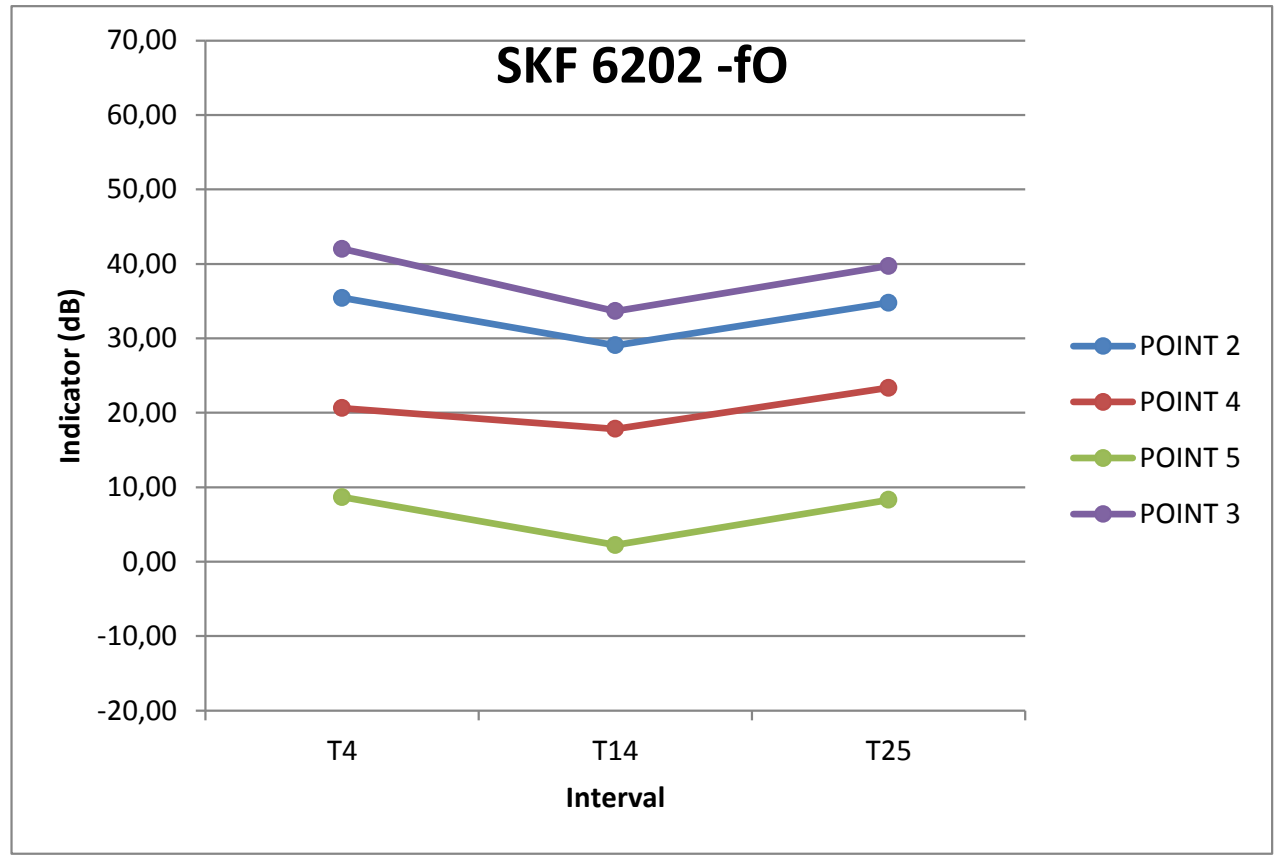

Figure 17. Graphical representation of the evolution of the fault severity indicator at each measurement point for the bearing SKF 6202 (fault component $f_{O}$ (outer raceway damage)). 


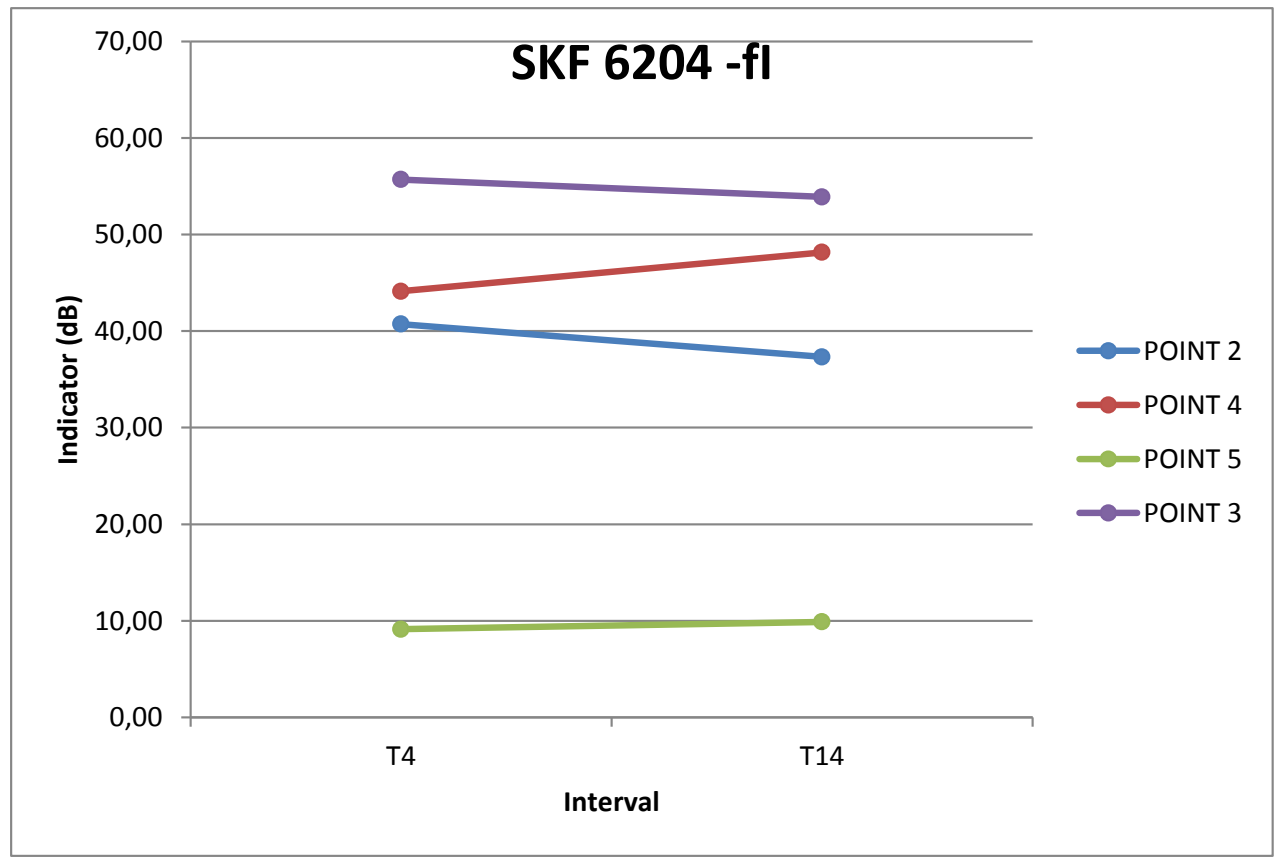

Figure 18. Graphical representation of the evolution of the fault severity indicator at each measurement point for the bearing SKF 6204 (fault component $f_{I}$ (inner raceway damage)).

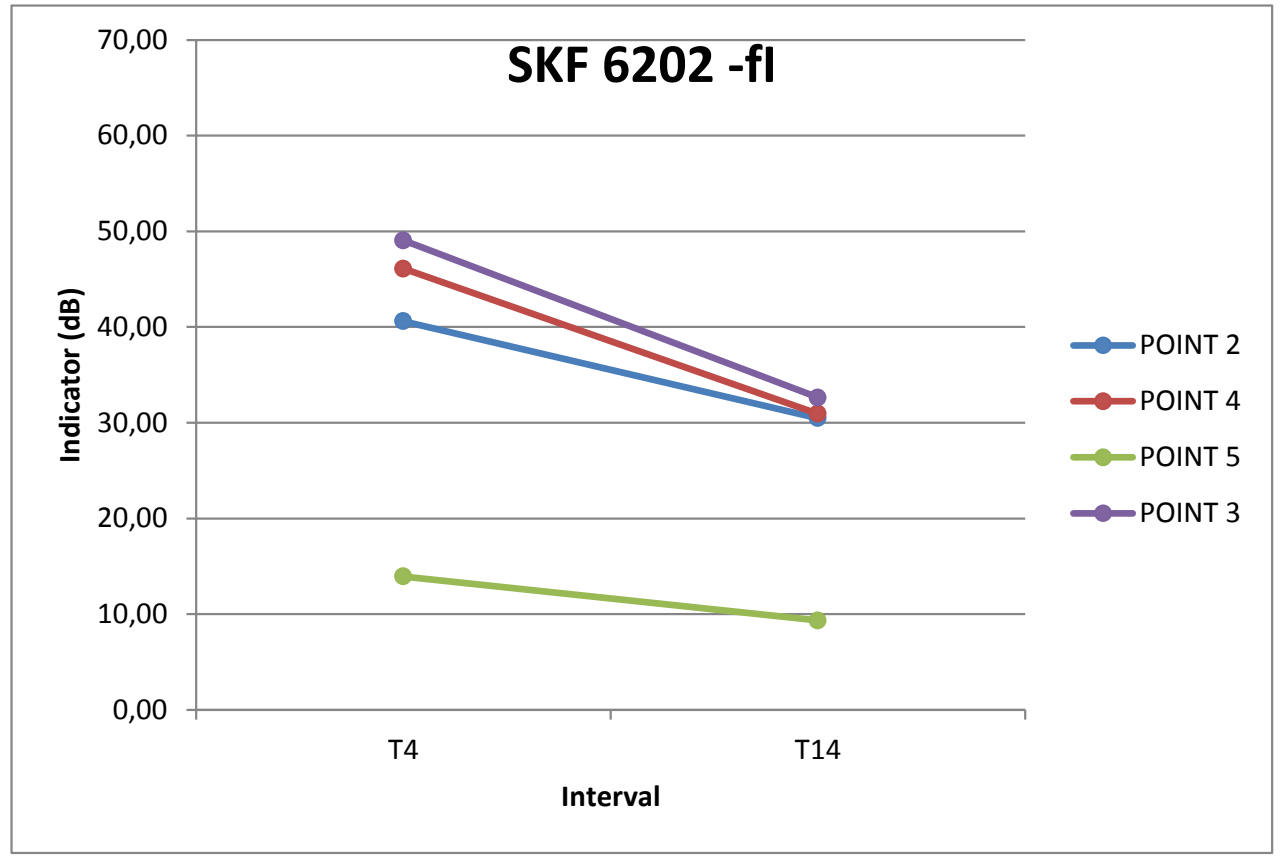

Figure 19. Graphical representation of the evolution of the fault severity indicator at each measurement point for the bearing SKF 6202 (fault component $f_{I}$ (inner raceway damage)). 


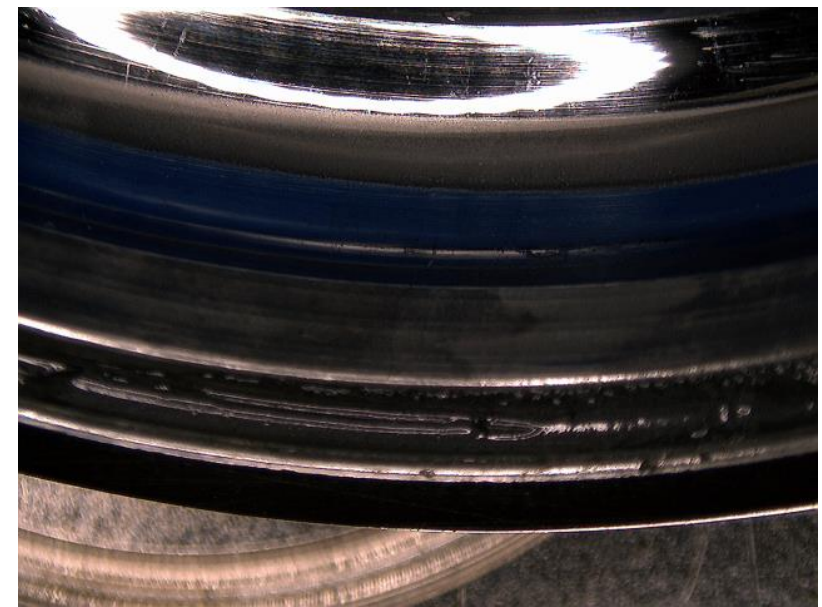

(a)

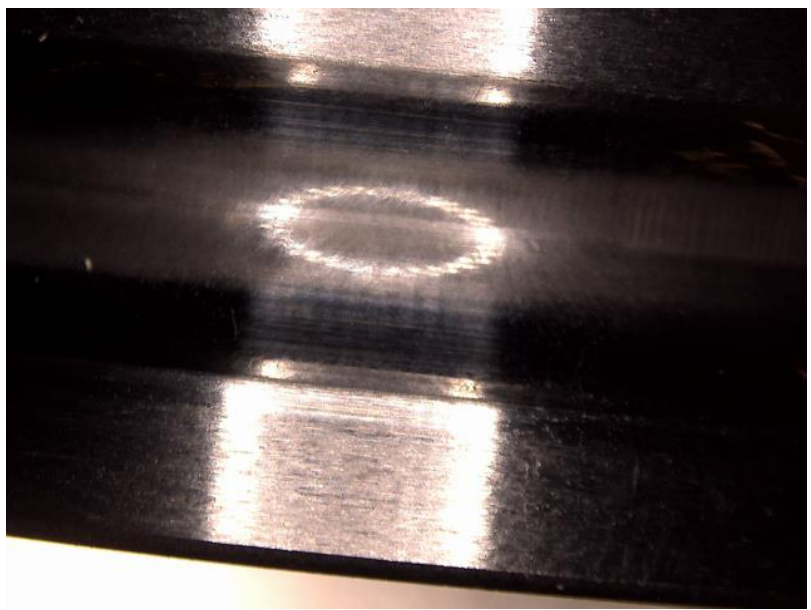

(b)

Figure 20. Pictures of the bearing SKF 6204 after its disassembly: (a) Outer raceway; (b) Inner raceway. 